\title{
Keys to Differentiating between Small- and Large-Drop Icing Conditions in Continental Clouds
}

\author{
BEN C. BERNSTEIN \\ Leading Edge Atmospherics, Longmont, Colorado \\ ROY M. RASMUSSEN \\ National Center for Atmospheric Research, Boulder, Colorado \\ FRANK MCDONOUGH \\ Desert Research Institute, University of Nevada, Reno, Nevada \\ CORY WOLFF \\ National Center for Atmospheric Research, Boulder, Colorado \\ (Manuscript received 6 February 2018, in final form 15 April 2019)
}

\begin{abstract}
Using observations from research aircraft flights over the Great Lakes region, synoptic and mesoscale environments that appear to drive a relationship between liquid water content, drop concentration, and drop size are investigated. In particular, conditions that fell within "small drop" and "large drop" regimes are related to cloud and stability profiles, providing insight regarding whether the clouds are tied to the local boundary layer. These findings are supported by analysis of flight data from other parts of North America and used to provide context for several icing incidents and accidents where large-drop icing was noted as a contributing factor. The relationships described for drop size discrimination in continental environments provide clues that can be applied for both human- and model-generated icing forecasts, as well as automated icing algorithms.
\end{abstract}

\section{Introduction}

It is well known that in-flight icing caused by aircraft encounters with supercooled liquid water can pose a significant safety hazard. This is especially true for supercooled large-drop (SLD) icing, which has been identified as a contributing factor in numerous accidents [e.g., National Transportation Safety Board (NTSB) 1996, 2002, 2006, 2007; Green 2006, 2015]. Over the last $\sim 30$ years, extensive flight, engineering and meteorological research has greatly improved the understanding of SLD icing and its effect on aircraft. This research and prolonged cooperation between regulatory agencies, aircraft manufacturers, scientists and engineers has culminated in new regulations that will require aircraft not certified for flight in freezing drizzle

Corresponding author: Ben C. Bernstein, icingweather@ gmail.com
(FZDZ) and/or freezing rain (FZRA) to avoid these conditions and to escape all icing after inadvertent encounters with them (FAA 2015; Cober and Isaac 2012). To adhere to the new regulations, pilots, dispatchers, and air traffic controllers will need more accurate, precise, high-resolution diagnoses and forecasts of drop size to allow for critical decisions relative to the certification and safety of their aircraft (DiVito and Riley 2017).

Three primary meteorological factors characterize icing conditions: temperature $(T)$, liquid water content (LWC), and the drop size distribution (DSD). Drop size is particularly important to the location and shape of ice that forms on aircraft surfaces, which can have dramatic impact on lift, drag and even the ability to maintain control (e.g., Ratvasky et al. 2010; Sand et al. 1984; Politovich 1989). When aircraft surface temperatures are sufficiently cold (several degrees below freezing), the impact of small supercooled drops tends 
to result in rime ice near the leading edge of the wing and other surfaces, while larger drops, including SLD, have a greater tendency to result in mixed or clear ice formation, sometimes well aft of ice protection systems (Fig. 1; Messinger 1953).

Human- and numerical-model-generated forecasts of $T$ are reasonably accurate, while LWC and drop size remain challenging, but have improved dramatically (e.g., Thompson et al. 2008, 2017a). In nature, drop concentrations can vary between tens and thousands per $\mathrm{cm}^{3}$ (e.g., Hudson and Yum 2001) but until recently, many models used fixed, median values of drop concentration across the domain, such as $100 \mathrm{~cm}^{-3}$ in the Rapid Update Cycle (RUC) and High-Resolution Rapid Refresh (HRRR). Such an approach served as a compromise until the explicit prediction of aerosols and subsequent drop concentration became computationally practical. Recently, modelers have started to address this issue by using a microphysics package that allows drop concentrations to vary based on source air and evolve via precipitation and other processes (Thompson and Eidhammer 2014; Thompson et al. 2017a,b). Even as microphysics schemes advance, the question remains: when should models and forecasters expect clouds dominated by small drops to convert to drizzle via collision-coalescence? In nature, this tends to happen relatively quickly in maritime environments (e.g., Rosenfeld et al. 2013), but the transition is more difficult to quantify in continental environments, where small drops tend to dominate, yet SLD is still commonly observed (e.g., Cortinas et al. 2004; Rauber et al. 2000; Cober et al. 2001; Geresdi et al. 2005; Williams et al. 2015).

As part of several field programs conducted between 1997 and 2005, meteorologists from the National Center for Atmospheric Research (NCAR) guided the NASA Glenn Research Center (NASA-GRC) Twin Otter, the National Research Council of Canada Convair-580, and other research aircraft into a wide variety of icing environments, many of which included SLD (Miller et al. 1997; Isaac et al. 2001, 2005). In addition, the lead author has spent the last 16 years guiding commercial test aircraft into supercooled clouds, targeting specific combinations of $T$, LWC, and drop size for the purpose of achieving icing certification (Bernstein et al. 2006a, 2011; Bernstein and Flemming 2007; Kubryn et al. 2011). Through this experience, case studies and climatological research, meteorological structures and patterns have emerged that relate to characteristic combinations of LWC, drop concentration (CONC), and the presence of SLD.

In this paper, NASA-GRC research aircraft observations will be used to establish further that a balance

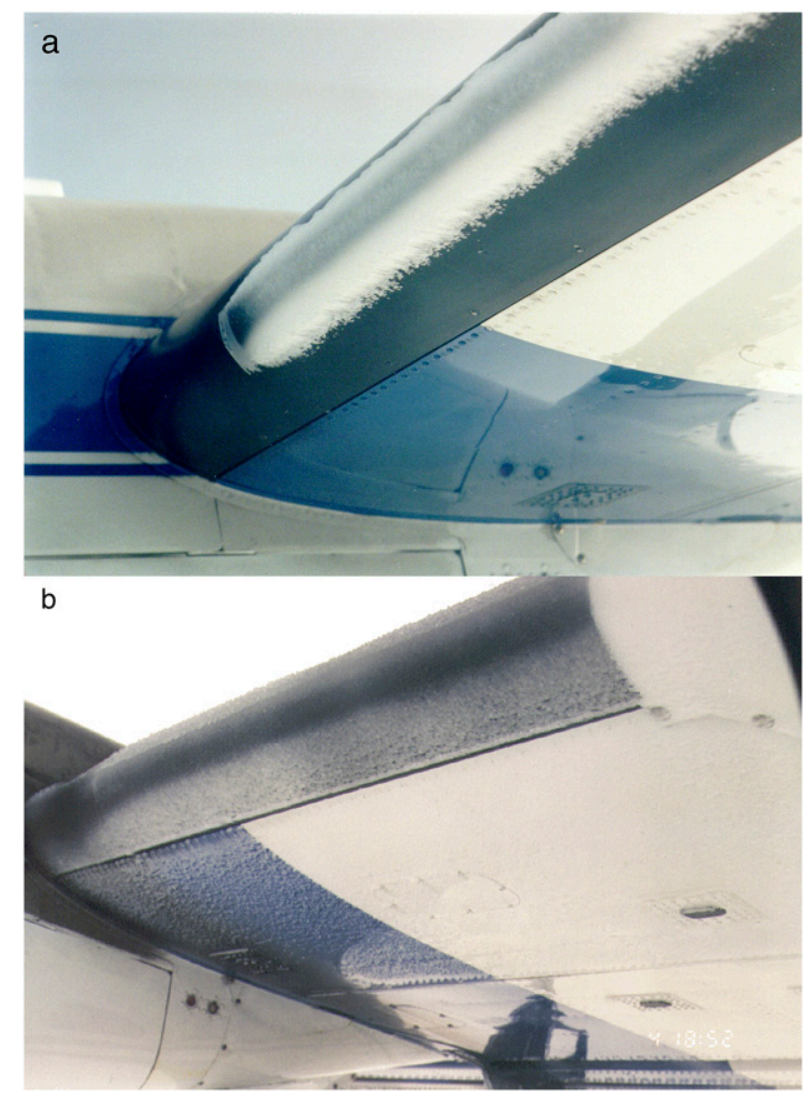

FIG. 1. Photos of the NASA Glenn Research Center's Twin Otter wing with small-drop and large-drop icing.

between LWC and CONC strongly relates to the production of supercooled clouds that are composed of cloud droplets ("small drop" events) versus those that include SLD ("large drop" events). These data, and those from other flight programs, will be placed into the context of synoptic patterns, thermodynamic structures, and patterns in satellite imagery and radar reflectivity to understand better the mechanisms that drive drop size in continental air masses. Such information may provide forecasters and modelers with valuable clues to differentiate between small- and large-drop icing situations.

\section{Datasets and case selection}

\section{a. Twin Otter research aircraft}

Between 1996 and 2005, NASA-GRC's Twin Otter documented a broad spectrum of icing events in the Great Lakes region (Fig. 2). Standard measurements were made for state parameters and cloud microphysics, with a "King" hot-wire probe for LWC (King et al. 1978), a Forward Scattering Spectrometer Probe (FSSP) for the cloud droplet size distribution and an Optical Array 2D-cloud probe (2DC) to capture 


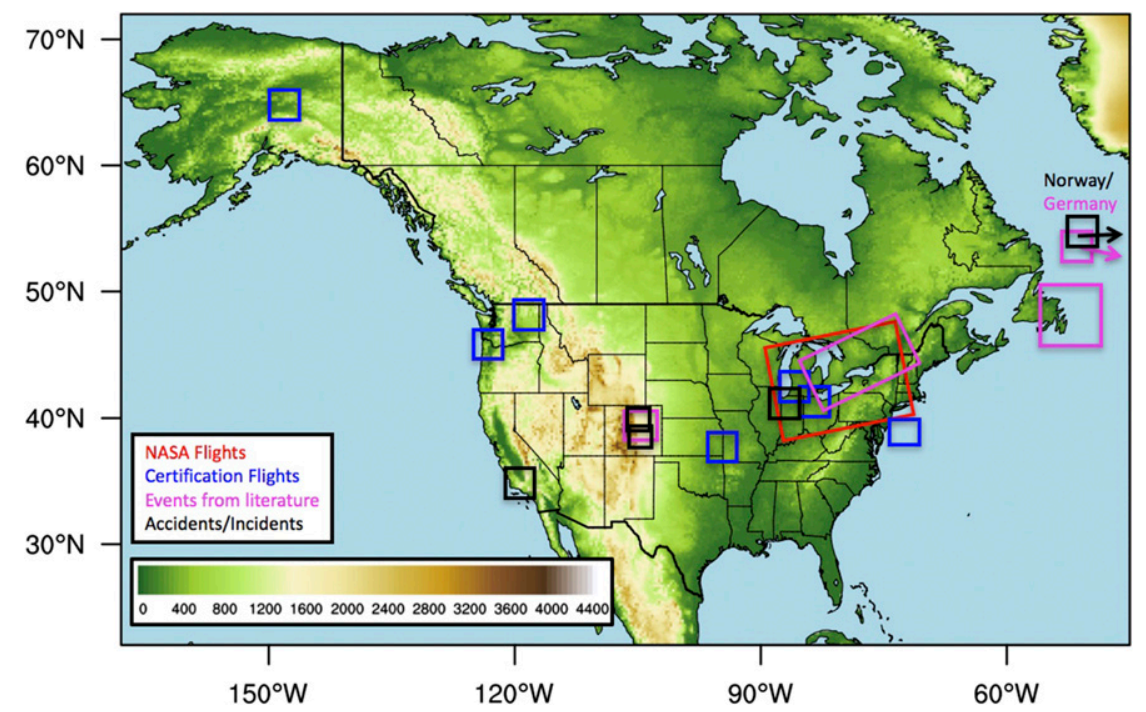

FIG. 2. Locations of the flights and events described in this paper. Boxes indicate the approximate position of the flights, color-coded to identify the event types and research programs during which samples were made.

particle images with $\sim 25-\mu \mathrm{m}$ resolution. King probes respond well to cloud droplets, but underestimate LWC from drops with diameters larger than $\sim 50 \mu \mathrm{m}$ (Biter et al. 1987; Strapp et al. 2003). Thus, for the purpose of this study, the King-probe measured LWC should be considered to essentially represent the "cloud-droplet liquid water content," rather than fullspectrum LWC. Likewise, FSSP-based CONC and median volumetric diameter (MVD) values only accounted for the cloud-droplet portion of the spectrum, rather than the full drop size spectrum. Ten-second averages of these fields will be presented. The NASA crew also took in-flight and postflight photos and documented changes in flight characteristics. It is important to note that aerosol measurements were not taken by the Twin Otter, nor were any such measurements available for any of the flights presented in this paper.

\section{b. Certification aircraft}

To complement the Twin Otter dataset, observations from instrumented aircraft seeking icing certification will also be presented. When aircraft manufacturers test new aircraft in icing, they rely on probes similar to those used in research, with similar limitations to those described above. Instrument suites employed for certification include hot-wire LWC probes [King, JohnsonWilliams/Science Engineering Associates, or Droplet Measurement Technology (DMT)], cloud droplet sizing probes [FSSP or a DMT Cloud Droplet Probe (CDP)], and in many cases a particle imaging probe [2DC or DMT Cloud Imaging Probe (CIP); see Strapp et al. 2003].
Icing certification flight tests required that the aircraft be exposed to an engineering design envelope covering specific ranges of $T$, LWC, and drop size, expressed as MVD. Exposures to icing range from $\sim 2$ to $45+$ min, during which ice accretions are built, from initial indications of ice to accretions that may exceed 3 in. on leading edge surfaces. Such accretions are maintained while pilots and engineers test aircraft systems and perform maneuvers (FAA 1999). Highquality measurements of the icing environments sampled are a critical part of the body of evidence that is submitted to aviation authorities for certification. Thus, the probes must be well maintained and frequently calibrated. Certification flights discussed herein were conducted throughout the United States, including areas far from the Great Lakes (Fig. 2).

\section{c. SLD determination and case selection}

For the purposes of this study, SLD are defined as drops that were fully shadowed on the 2DC or CIP probes with diameters $>\sim 125 \mu \mathrm{m}$, the minimum size for particle phase discrimination. The presence or absence of SLD and ice crystals was determined via visual inspection of probe imagery and consultation of flight notes. All SLD cases presented in this study appear to have formed via the collision-coalescence process (Huffman and Norman 1988), with no evidence of the "classical freezing rain" process (Bocchieri 1980), where snow melts then falls into a lower subfreezing layer to become supercooled.

The events sampled occurred within a variety of synoptic environments and vertical structures, including a 


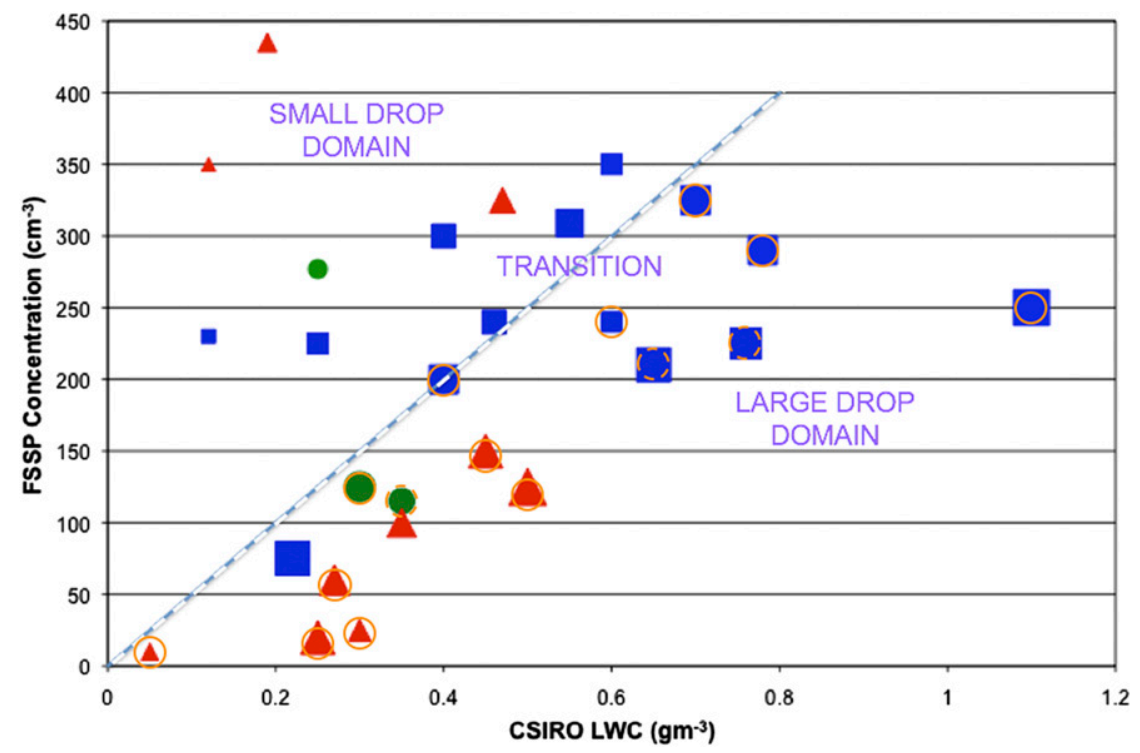

FIG. 3. LWC vs CONC for the 27 Twin Otter cases. Markers are colored and shaped by the predominant temperature advection present: warm (red triangles), cold (blue squares), and neutral (green circles). Marker size is proportional to FSSP-measured MVD. SLD events are marked with tan circles. Out-of-focus, borderline SLD events are marked with dashed circles. A diagonal, dashed line indicates a $2 \times 10^{-9} \mathrm{~g}$ ratio of LWC:CONC, indicated as the transition between the small-drop domain, where all cases were dominated by cloud droplets, and the large-drop domain, where most cases featured SLD.

range of stability profiles and both single-layer and multilayered clouds. To gain insight on the environmental effects on LWC, CONC, and DSD, Twin Otter samples used were limited to cloud layers that were 1) dominated by supercooled liquid water (SLW), with few or no ice crystals, and 2) isolated from higher cloud layers, eliminating the potential for seeding from above. Only samples made near cloud top are used. Events were only included when microphysical data were considered to be of good quality, with hot-wire LWCs that were self-consistent, tracked well with those from the FSSP and were consistent with data from other sources, including vertical profiles were made by the aircraft and/or radiosondes launched nearby in time and space. In all, 27 Twin Otter events met these criteria. All Twin Otter samples occurred between November and March at altitudes of $\sim 900-4300 \mathrm{~m}$ (all heights MSL) and at $T$ between $-14^{\circ}$ and $-1{ }^{\circ} \mathrm{C}$.

Certification program flights have been conducted over a broader domain, including more than 40 U.S. states, as well as Canada and Europe. Samples were obtained during all months of the year except July and August, covered a broader range of altitudes $(\sim 900-7600 \mathrm{~m})$ and temperatures $\left(0^{\circ}\right.$ to $\left.-30^{\circ} \mathrm{C}\right)$. To date, more than $500 \mathrm{~h}$ of certification flight data have been collected from more than 100 flights. A small subset of flights made over the United States, including Alaska, will be used to demonstrate that conditions similar to those observed by the Twin Otter were also found over a broader domain (Fig. 2).

\section{Twin Otter icing environments}

\section{a. Overview}

A scatterplot of LWC and CONC for the Twin Otter cases shows that LWC and CONC values ranged from 0.07 to $1.1 \mathrm{~g} \mathrm{~m}^{-3}$ and 10 to $435 \mathrm{~cm}^{-3}$, respectively (Fig. 3). The occurrence of small versus large drops follows expectations from collision-coalescence theory (Pruppacher and Klett 1978). As cloud droplets increase in size, the process of growth through collisioncoalescence becomes increasingly important and leads to the production of drops with diameters up to and exceeding $\sim 100 \mu \mathrm{m}$. In cases where CONC was toward the high end of the spectrum in Fig. $3\left(>\sim 300 \mathrm{~cm}^{-3}\right)$, drops tended to be small (cloud droplets, no SLD) unless LWCs reached rather high values $\left(>\sim 0.6 \mathrm{~g} \mathrm{~m}^{-3}\right)$. When CONC was toward the low end of the spectrum $\left(<\sim 100 \mathrm{~cm}^{-3}\right)$, SLD was much more common, even with $\mathrm{LWC}<0.25 \mathrm{~g} \mathrm{~m}^{-3}$. This is consistent with previous observations and bin microphysics studies (Rasmussen et al. 2002).

A transition zone between small- and large-drop environments slants from lower left to upper right in Fig. 3. 
This is expected, since drop sizes should increase when (i) LWC increases while CONC is held steady or (ii) LWC is held steady while CONC is decreased. The former tends to happen where clouds deepen, typically due to lower (and warmer) cloud base and/or higher (and cooler) cloud top, or due to decreases in the amount of glaciation. The latter tends to occur in transitions to pockets/areas of relatively clean air. Both can show up during a given flight, where LWC, MVD, and the presence/absence of SLD can vary spatially and temporally. Both types of transitions appear to be associated with DSD broadening, sometimes to the point where collision-coalescence is initiated and SLD forms. The transition zone is located roughly along the line where the LWC to CONC ratio is $\sim 0.2 \mathrm{~g} \mathrm{~m}^{-3}$ per $100 \mathrm{~cm}^{-3}$.

Ten cases fell within the "small drop" domain, up and to the left of the transition zone, where low FSSP MVDs $(8-15 \mu \mathrm{m})$ were found and SLD was not observed. One case landed on the transition line and 16 cases fell into the "large drop" domain, where MVDs were relatively large (15-22 $\mu \mathrm{m})$ and SLD was often present (11 cases). Somewhat smaller, out of focus drops were present in 3 of the 5 remaining "large drop" domain cases. Small drops were present in every case and were often the primary contributor to the LWC. Recall that the King probe responds best to cloud droplets and FSSP CONC values only cover the cloud-droplet portion of the spectrum. Thus, some of the large-drop cases may have had larger full-spectrum LWC, CONC, and MVD, potentially moving some markers up and to the right, and making them larger.

Two cases in the "large drop" domain did not have indications of SLD. Those cases had MVD between 17 and $20 \mu \mathrm{m}$, rather narrow DSDs, and few, if any drops larger than $30 \mu \mathrm{m}$. A vertical profile of aircraft data was available for one of these clouds and it featured a narrow DSD that shifted gradually toward larger sizes, with MVD increasing from $\sim 10$ to $20 \mu \mathrm{m}$ between cloud base and cloud top (not shown). For this case, spectral broadening may not have occurred yet, if at all, despite the presence of favorable ratios of LWC to CONC.

It is important to note that, although the Twin Otter cases in the small-drop domain had MVD of 8-15 $\mu \mathrm{m}$, icing conditions with MVD $>15 \mu \mathrm{m}$ have been commonly found in clouds without SLD during research and certification flights. The reader should also bear in mind that data points in Fig. 3 were from a limited geographic domain, and only represent supercooled, liquid-dominated clouds with a limited spectrum of LWC and CONC. Conditions outside these ranges certainly exist, but the data points in Fig. 3 are typical for supercooled clouds (Cober and Isaac 2006, 2012; FAA 1999, 2015). Although this paper is focused on supercooled clouds,

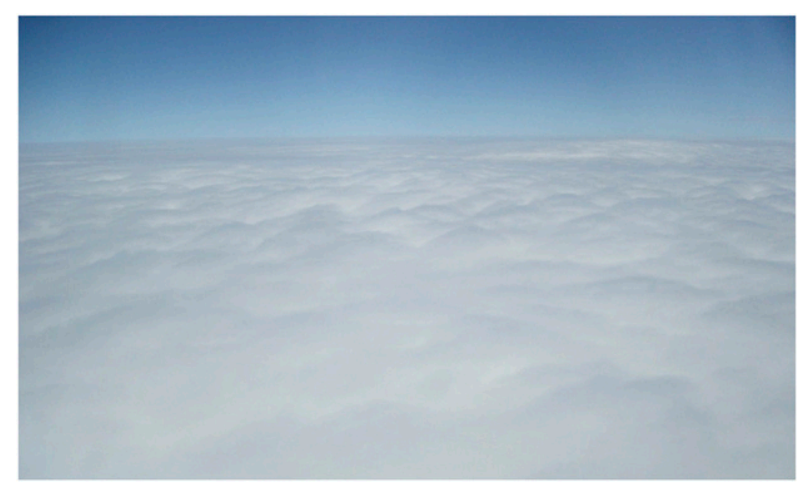

FIG. 4. Example of "quilted" stratocumulus cloud tops.

the concepts regarding drop size tendencies discussed in this paper apply to above-freezing clouds, as well (see Wood 2005).

\section{b. Variations on continental cloud environments}

Now that the Twin Otter cases have been broadly categorized, it is useful to examine some groupings of cases. Despite the basic idea that continental clouds often have high drop concentrations, it is common knowledge that significant variations in drop concentration can be found within them, and that these changes are likely associated with variations in cloud condensation nuclei (CCN). Such variations are apparent in some of the cases presented here. The structures associated with these variations and their effect on drop size are discussed below.

\section{1) CONTINental ClOUdS WITH HIGH DROP CONCENTRATIONS}

As might be expected, clouds with relatively high drop concentrations $\left(\geq 200 \mathrm{~cm}^{-3}\right.$; hereafter "high CONC") tended to be associated with air masses rooted in the boundary layer. Vertical temperature profiles often had dry-adiabatic lapse rates from the ground to cloud base, moist-adiabatic lapse rates within the cloud layer, and a capping stable layer at cloud top. This capped instability scenario often resulted in widespread stratocumulus clouds with uniform, "quilted" tops (Fig. 4).

Such situations are commonly found in the wake of cold fronts, where cold-air advection destabilizes the boundary layer (BL), and subsidence above the front limits vertical development. These layers are typically dominated by SLW in the form of small drops when the cloud-top temperatures are relatively warm (CTT $>\sim-12^{\circ} \mathrm{C}$ ), reducing the activation of ice nuclei (IN). Similar situations can sometimes be found within the "warm sector," where the boundary layer may be deeper, but is often still capped by a stable layer. Among the 17 cases with high CONC, 11 occurred behind cold 


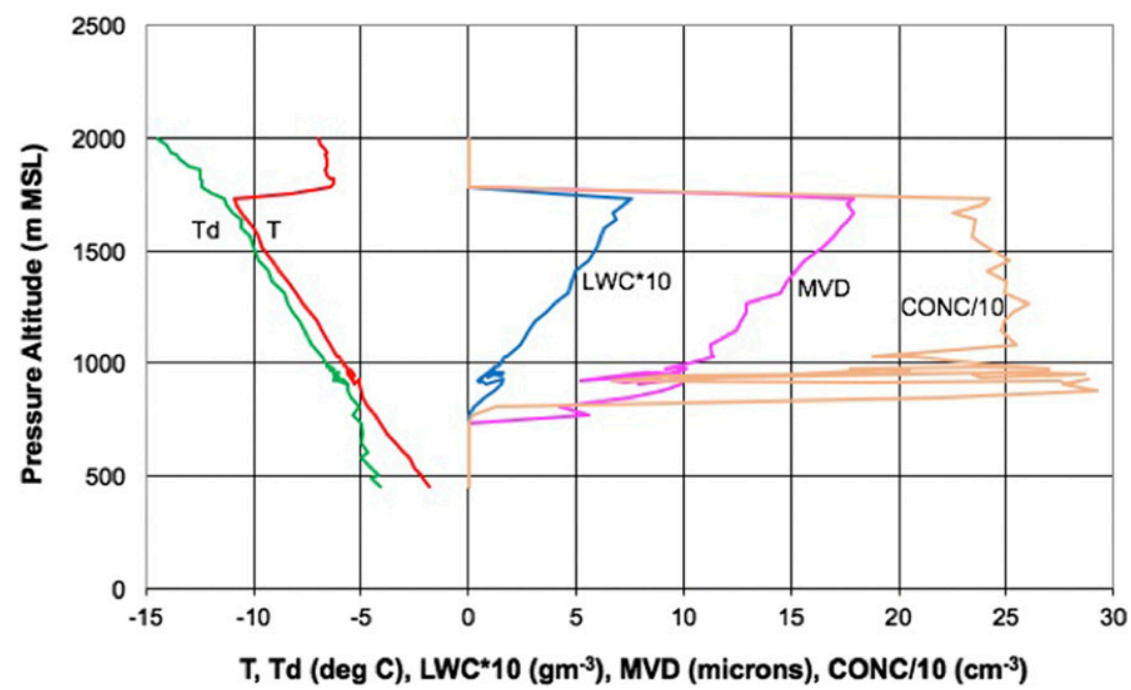

FIG. 5. Example vertical profile of 10 -s averages of temperature ( $T$; red), dewpoint temperature $\left(T_{d}\right.$; green), King LWC $\times 10\left(\mathrm{~g} \mathrm{~m}^{-3}\right.$; blue), FSSP MVD $\left(\mu \mathrm{m}\right.$; magenta), and CONC/10 $\left(\mathrm{cm}^{-3}\right.$; $\tan$ ) for a missed approach descent over Canton-Akron, Ohio, 1319-1331 UTC 30 Jan 1998. MVD and CONC were screened out for FSSP counts less than 10 to eliminate noise below cloud base.

fronts, 1 behind an occluded front, and 2 within the warm sector, while the remaining 3 occurred in illdefined synoptic environments. Cold-, neutral-, and warm-air advection (indicated as blue, green and red markers in Fig. 3) were found at the flight level for 13, 1 , and 3 cases, respectively.

In these BL clouds, LWC and MVD typically increased steadily with height, then rapidly decreased to zero at the cloud-top interface, while CONC values were reasonably consistent throughout the layer (e.g., Fig. 5; Martin et al. 1994; Reehorst et al. 2009). A climb through such a layer would essentially result in a move toward the right in Fig. 3. As noted earlier, if such a cloud was deep and/or warm enough to achieve a large LWC:CONC ratio, then SLD could form. Such was the case for the event shown in Fig. 5, where LWC reached $0.76 \mathrm{~g} \mathrm{~m}^{-3}$ and small drizzle formed.

A comparison of two boundary layer rooted events from 24 February 1998, when only cloud droplets were present, and 30 January 1998, when small drizzle was present, demonstrates this. Among them, the 30 January event had lower CONC (225 vs $\left.275 \mathrm{~cm}^{-3}\right)$, greater depth (1100 vs $300 \mathrm{~m})$, and much higher cloudtop LWC (0.76 vs $\left.0.25 \mathrm{~g} \mathrm{~m}^{-3}\right)$, resulting in a larger LWC:CONC ratio (0.34 vs 0.09$)$, and larger FSSPmeasured MVD (18 vs $11 \mu \mathrm{m}$; see Fig. 3). It is interesting to note that the drizzle developed on 30 January despite having colder CTT $\left(-11^{\circ}\right.$ vs $\left.-3^{\circ} \mathrm{C}\right)$, cloud-base $T\left(-5^{\circ}\right.$ vs $\left.-1^{\circ} \mathrm{C}\right)$, and lower cloud-base mixing ratio $\left(\sim 2.8 \mathrm{vs} \sim 3.9 \mathrm{~g} \mathrm{~kg}^{-1}\right)$. Given the relatively low temperature and mixing ratio at the base, colder tops were necessary for this cloud to achieve adequate depth to generate sufficient LWC at cloud top to allow SLD to form on 30 January.

With that in mind, it is important to note that CTT tends to be a limiting factor for the amount of LWC and drop size that can be achieved within BL clouds. As cloud layers deepen and LWC increases in moist-adiabatic lapse rates, $T$ (and thus, CTT) also decrease fairly rapidly (e.g., Fig. 5). Once CTTs cool beyond about $-12^{\circ} \mathrm{C}$, the preponderance of ice can increase in these clouds, resulting in at least partial glaciation at or just beneath cloud top and sometimes results in seeding of the remainder of the cloud below (e.g., Geresdi et al. 2005). The development of significant ice can also result in preferential seeding of drops toward the large end of the DSD, due to their higher collision efficiency with ice crystals. This can make it even more difficult for highly continental wintertime clouds to initiate collision-coalescence.

The 30 January case is notable because SLD did form in a relatively cold environment. CTT was $-11^{\circ} \mathrm{C}$ and both drizzle and light snow were observed at the surface for hours. Clearly, a balance was struck between drizzle and snow production in these clouds. BL clouds with relatively warm bases and tops have a greater chance of having sufficient LWC to generate SLD without significant ice production. Of course, when such a combination is combined with very low CONC, as in maritime cumulus, large drops are even more likely to form (e.g., Hudson and Yum 2001).

In addition, the conversion of the small drops to drizzle can also limit the LWC that a cloud can achieve, since a 

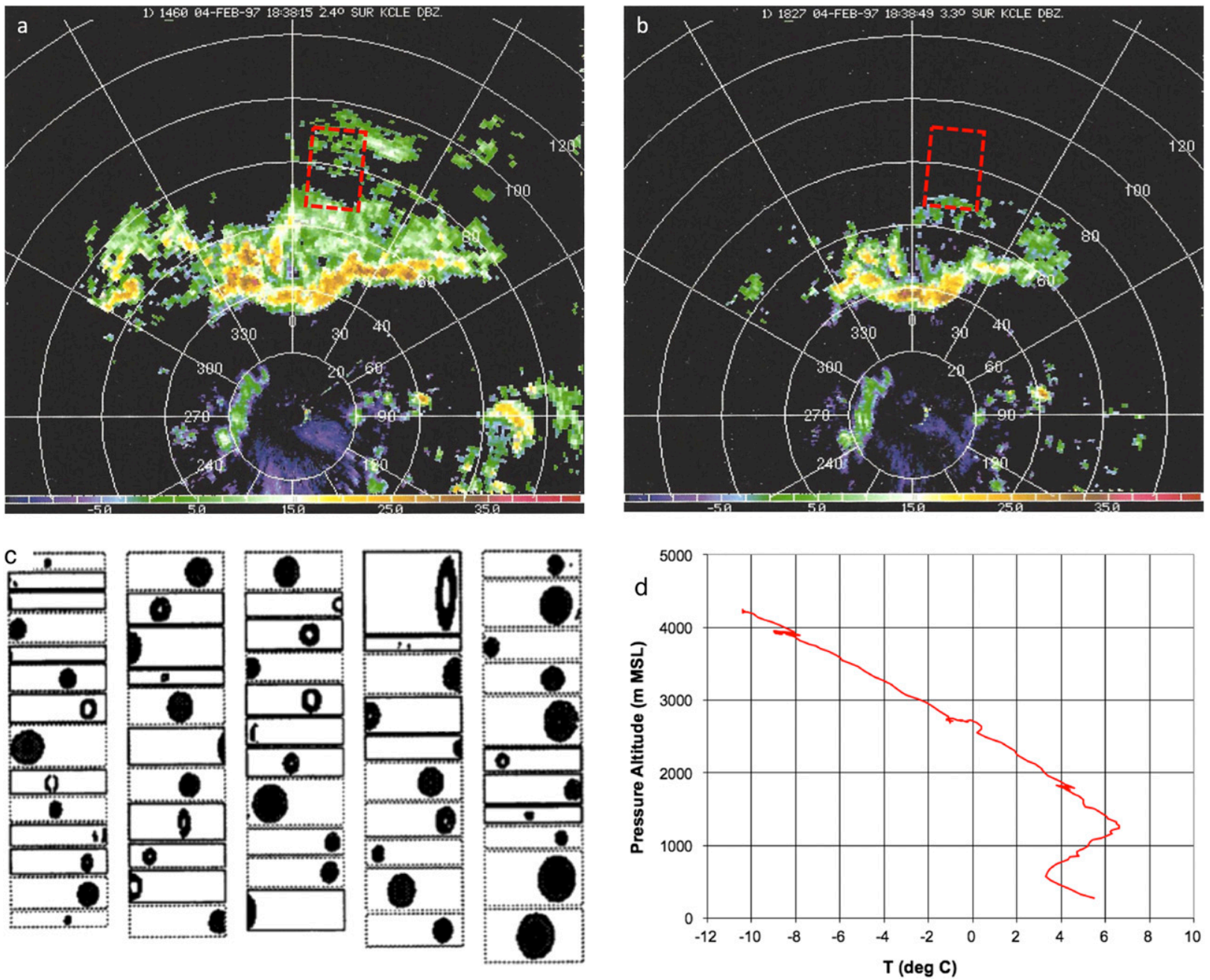

FIG. 6. Cleveland NEXRAD reflectivity from 1838 UTC 4 Feb 1997 taken at (a) $2.4^{\circ}$ and (b) $3.3^{\circ}$ elevations matching flight location (red dashed boxes) and altitude ( $\mathrm{m}$ MSL) for SLD event in and around gaps in showery precipitation. (c) PMS 2DC imagery from 1835 UTC at $\sim 4000 \mathrm{~m}$ and $-9^{\circ} \mathrm{C}$ (from Miller et al. 1998). (d) Vertical profile of temperature on climb out of Cleveland, 1754-1823 UTC.

portion of the SLW may precipitate out of the cloud. This occurred on 30 January, but precipitation rates were so light that the effect on LWC was likely minimal. Of course, if the updraft strength in a given cloud is sufficient to suspend the SLD, then the LWC can be maintained and the SLD can continue to grow. Because stronger updrafts tend to activate more $\mathrm{CCN}$ (Thompson and Eidhammer 2014; Feingold and Heymsfield 1992), a large number of smaller drops can result in rapidly rising, highly continental clouds. Thus, low-to-moderate vertical velocities may be optimal for allowing large-drop generation zones to persist when LWC:CONC ratios are appropriate.

\section{2) CONTINENTAL CLOUDS WITH LOW DROP CONCENTRATIONS}

All clouds with relatively low drop concentrations in Fig. 3 ( $<200 \mathrm{~cm}^{-3}$; hereafter "low CONC") were located above stable layers, many of which were strong and/or deep inversions. In otherwise continental environments, these stable layers isolated the clouds from local boundary layer sources of $\mathrm{CCN}$ and IN. Such situations are commonly found on the cold side (often north) of warm fronts and stationary fronts, where warm air often glides over a sloping stable layer. These clouds sometimes lose $\mathrm{CCN}$ and IN via precipitation processes, especially near the frontal zone (e.g., Rasmussen et al. 1995, 2002). Several of the low-CONC continental cloud cases on Fig. 3 developed within layers of instability above a stable zone (e.g., Fig. 6; as in Bernstein 2000). In these situations, LWC commonly increased with height in the elevated unstable layer, similar to BL clouds, but with lower CONC, making them more ideal for SLD production.

Among the 10 cases with $\mathrm{CONC}<200 \mathrm{~cm}^{-3}, 7$ of them were associated with warm-air advection, 2 with 
neutral advection and 1 with cold-air advection at flight level. Six cases occurred on the cold side of warm or stationary fronts, two occurred in the warm sector and two were associated with occlusions. Synoptic and structural tendencies described for low-CONC environments corroborate those found in climatological and regional studies of FZDZ events (Bernstein et al. 1998; Bernstein 2000).

Several of the low-CONC SLD cases occurred in areas just outside or within breaks in precipitation. An excellent example occurred on 4 February 1997, where strong patches of SLD icing were observed in gaps between showers and resulted in one of the largest performance degradations experienced by the Twin Otter during the test programs (Miller et al. 1997). This event formed in a fairly deep, unstable layer above a $3^{\circ} \mathrm{C}$ inversion (Fig. 6). Snow and relatively little LWC were found within the higher reflectivity areas. While such situations fit the scenario of continental, lowCONC environments in elevated instability described above, they may also support the idea of localized cleansing of the air, removing some CCN and IN (e.g., Rasmussen et al. 1995; McDonough and Bernstein 2004), and allowing SLD to develop in newly formed liquid water clouds with diminished CONC between and/or downstream of the showers.

\section{c. Local variability}

The local variability described in the previous section has been noted in past studies (e.g., Sand et al. 1984; Cober et al. 2001; Jeck 2002; Wood 2005; LasherTrapp et al. 2008; Hauf and Schroeder 2006). Variability in LWC, CONC, and MVD during a flight is typically linked to local changes in cloud depth, cloudbase and cloud-top temperature, presence of showers, source air, etc. This can sometimes result in sporadic SLD, perhaps due to transitions between less and more favorable LWC:CONC ratios. Such changes can result in significant local differences in the effects that the ice may have on aircraft passing through an area. Localscale variability may have played a role in some accidents, such as the 1997 crash of an Embraer (EMB)-120 near Detroit, Michigan, where a series of aircraft were flying the same approach through snow showers and icing. In postaccident interviews, the pilots reported the icing as "none," "light," "moderate-to-severe," and "as bad as I've ever seen it" (NTSB 1998).

\section{d. Capping stable layers and drop size}

It is interesting to note that every cloud examined in this study was capped by a stable layer, and several were capped by strong inversions over shallow depths (e.g., Fig. 5). SLD was present in some of these clouds, but many only had small drops. Although finescale wind data were not available from the Twin Otter, soundings and synoptic-scale weather data indicated that at least some wind shear was present in most, if not every event. It was not possible to determine whether the shear was strong enough to initiate turbulent mixing with the dry air above cloud top. Cloud tops were more commonly "quilted," as described earlier, or relatively flat and nondescript.

While SLD certainly can occur in the presence of dynamically unstable layers near cloud top associated with wind shear, as proposed by Pobanz et al. (1994), the results presented here imply that their simultaneous presence may not be necessary for SLD to develop. Rather, the controlling factors appear to be whether 1) an adequate ratio of LWC:CONC is present, 2) the below-cloud and/or in-cloud stability structure limits the contribution of local BL sources $\mathrm{CCN}$ and IN, and 3) ice concentrations are sufficiently small to limit scavenging of liquid water, especially at the large end of the DSD. That said, mixing and localized areas of supersaturation may still play an important role, as demonstrated by Korolev and Isaac (2000).

\section{Supporting evidence from certification flights}

The certification flight dataset provides some examples of similar environments and trends over broader geographic and temperature domains. While guiding aircraft into icing conditions for certification over 16 years, many cases have proven interesting, but it is only practical to highlight a few that shed additional light on the relationships between drop size and the LWC:CONC ratio. Aircraft manufacturers names and the dates of the cases described below have been omitted to maintain client anonymity. A brief summary of the conditions observed and meteorological features associated with each flight in sections 4 and 5 is provided in Table 1.

One April flight along the Kansas-Missouri border was made into a cloud that had two layers separated vertically by a $500-\mathrm{m}$ deep, $2^{\circ} \mathrm{C}$ inversion. The initial climb through the clouds revealed that the lower cloud was rooted in the boundary layer, while the upper cloud appeared to be somewhat isolated from the boundary layer (Fig. 7). LWC within the clouds peaked at 0.59 and $0.53 \mathrm{~g} \mathrm{~m}^{-3}$ at their respective $-8^{\circ}$ and $-7^{\circ} \mathrm{C}$ cloud tops. MVDs peaked at 20 and $26 \mu \mathrm{m}$ near the top of each layer, illustrating the importance of subtle differences in drop concentration in these two highly comparable clouds. Although particle imagery was not available for this case, smooth areas of low reflectivity, typical of drizzle (Ikeda et al. 2009) were evident on radar data in 


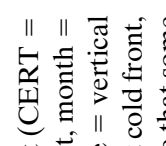

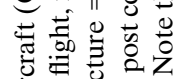

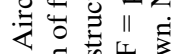

"ng

cot

है

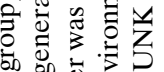

.

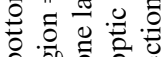

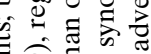

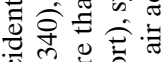

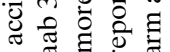

च

의월

焉 03

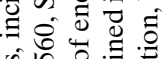

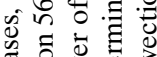

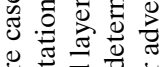

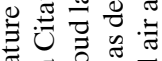

苟 $\frac{0}{0} \frac{0}{0}$

U సี ॥\|

青

实墕

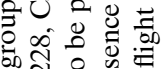

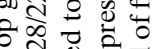

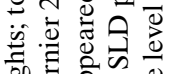

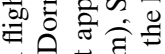

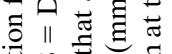

댕

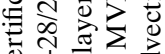

过

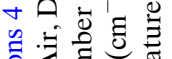

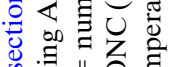

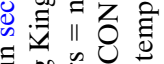

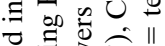

है

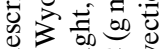

प

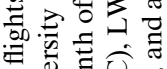

응

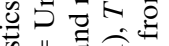

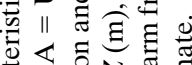

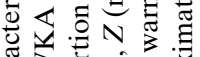

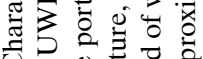

ठ․

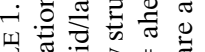

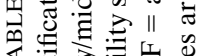

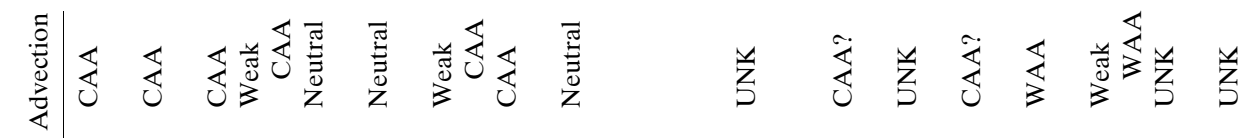

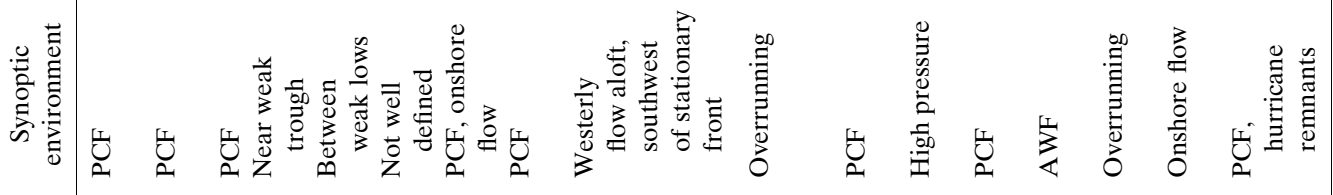

究 y y

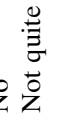

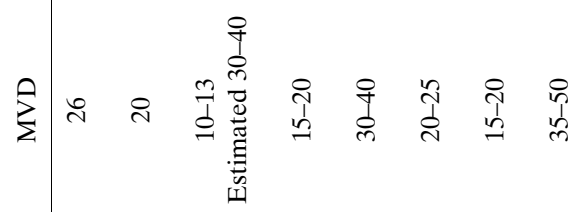

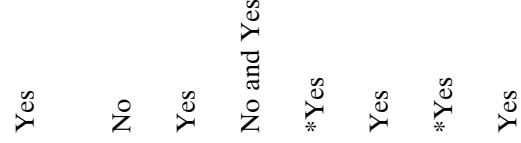

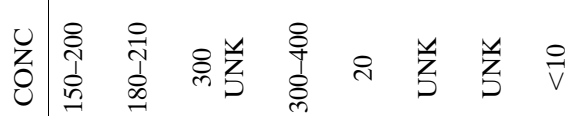

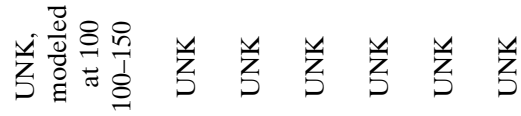

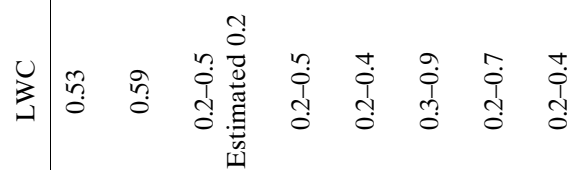

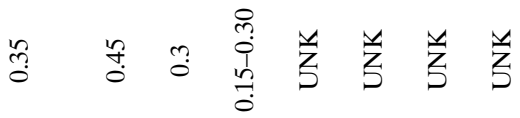

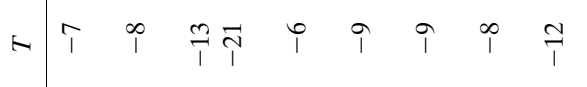

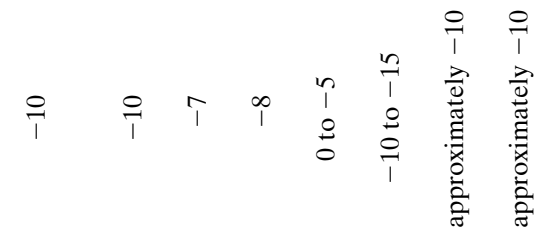

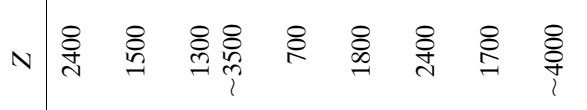

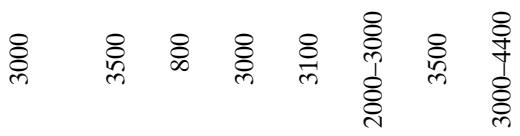

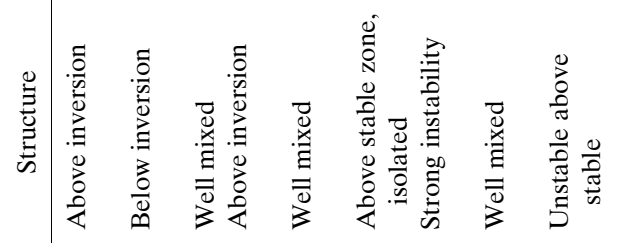

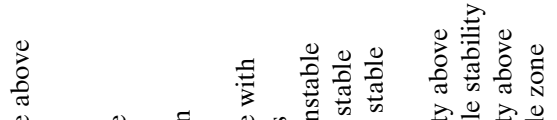

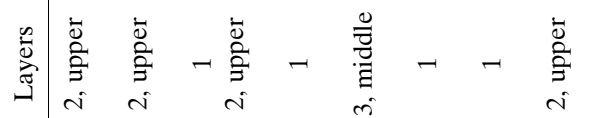

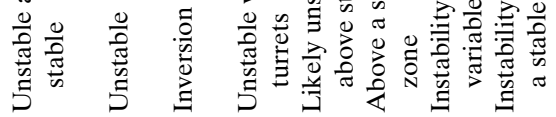

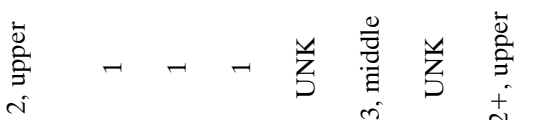

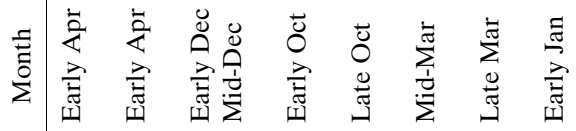

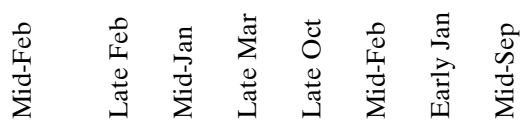

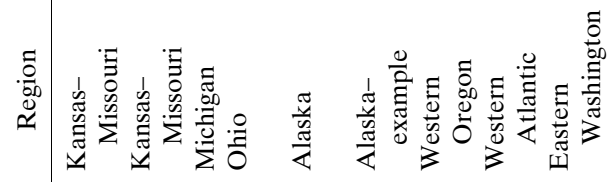

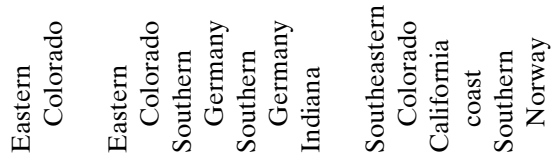

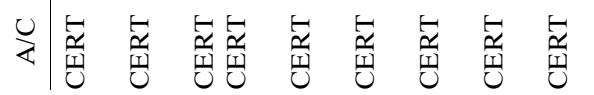

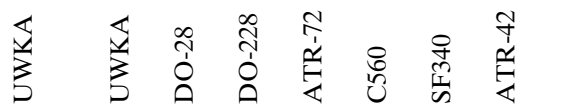




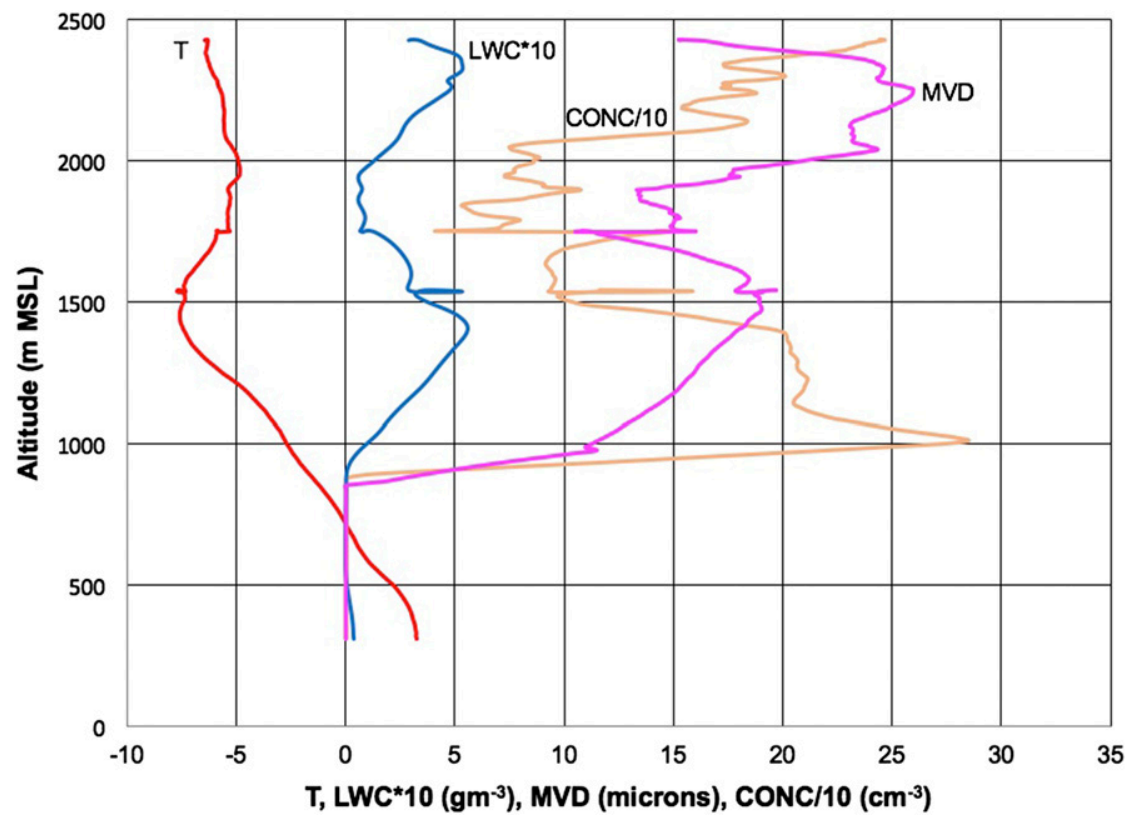

FIG. 7. Vertical profiles of temperature (SAT; $\left.{ }^{\circ} \mathrm{C}\right)$, liquid water content $\left(\mathrm{LWC} ; \mathrm{g} \mathrm{m}^{-3}\right)$, median volumetric diameter (MVD; $\mu \mathrm{m})$, and FSSP total concentration $\left(\mathrm{cm}^{-3}\right)$ from a two-layer cloud situation with changes in MVD across an inversion. Dewpoint temperature was not available.

the area of sampling and nearby surface stations reported mist, drizzle and very light rain (not shown).

An example of a very small-drop icing event occurred immediately downwind of Lake Michigan following an early December front that brought very cold air across the lake, similar to events described by Kristovich and Laird (1998). The surface $T$ of the lake was $+9^{\circ} \mathrm{C}$, while $T$ at the flight level $(\sim 1300 \mathrm{~m})$ was $-13^{\circ} \mathrm{C}$. This combination of steep lapse rates and cool CTTs resulted in cellular stratocumulus clouds and $15-25 \mathrm{dBZ}$ snow showers. Cloud-top LWCs were highly variable $\left(0.2-0.5 \mathrm{~g} \mathrm{~m}^{-3}\right)$, CONCs were on the order of $300 \mathrm{~cm}^{-3}$, and MVDs were only $10-13 \mu \mathrm{m}$, with no indication of large drops. The ratio of even peak LWCs to CONC would have placed it within the smalldrop domain of Fig. 3. The presence of small MVDs is supported by a combination of young, regenerating clouds with relatively high CONC, plus a rapid transition to snow just below the top, which may be associated with preferential seeding of the larger drops in the spectrum (Geresdi et al. 2005).

One very different, rather cold case was sampled in clouds $\sim 3000 \mathrm{~m}$ above a strong stable layer that was capping some low, warm clouds over northwestern Ohio. Although probe data were not available for this case, the encounter with vertically isolated, $-21^{\circ} \mathrm{C}$ liquid cloud tops resulted in a mixed-ice accretion on the deicing boots. The aft extent of this ice was compared to results from LEWICE (Wright 1999) tests conducted before the flight program, which identified expected ice accretion limits for specific MVDs within FAA appendix C. These limits were clearly marked on the boots for reference. Postflight analysis photographs and videos of the ice accretions resulted in MVD estimates of 30-40 $\mu \mathrm{m}$. Numerous other aircraft exposed to this cloud reported moderate severity mixed ice, with one Boeing-757 reporting moderate-to-severe mixed ice. The presence of enhanced drop sizes is further supported by satellite infrared derivatives that provide indications of particle size near cloud top (Lee et al. 1997; Fig. 8). Icing with relatively large drops at $-20^{\circ}$ to $-30^{\circ} \mathrm{C}$ is often fleeting in nature. However, the slow-moving cloud layer that caused this event persisted for several days, resulting in dozens of reports of moderate or greater icing around Minneapolis, Minnesota; Chicago, Illinois; Detroit, Michigan; Cleveland, Ohio; Pittsburgh, Pennsylvania; and Buffalo, New York. This case suggests that a cold cloud layer isolated from the boundary layer can maintain enhanced drop sizes for extended periods.

One event near Fairbanks, Alaska, was typical of BL clouds that develop over the Tanana River during autumn, when the bare ground is still exposed and air masses tend to be highly continental. On this day, a 300-m thick cloud layer with a strong capping inversion was present. Several aircraft penetrations through the cloud tops resulted in consistent encounters with LWC up to $0.5 \mathrm{~g} \mathrm{~m}^{-3}$, CONC of $300-400 \mathrm{~cm}^{-3}$, and MVD of $15-20 \mu \mathrm{m}$ at $-6^{\circ} \mathrm{C}$. Later in the fall, when snow cover and 

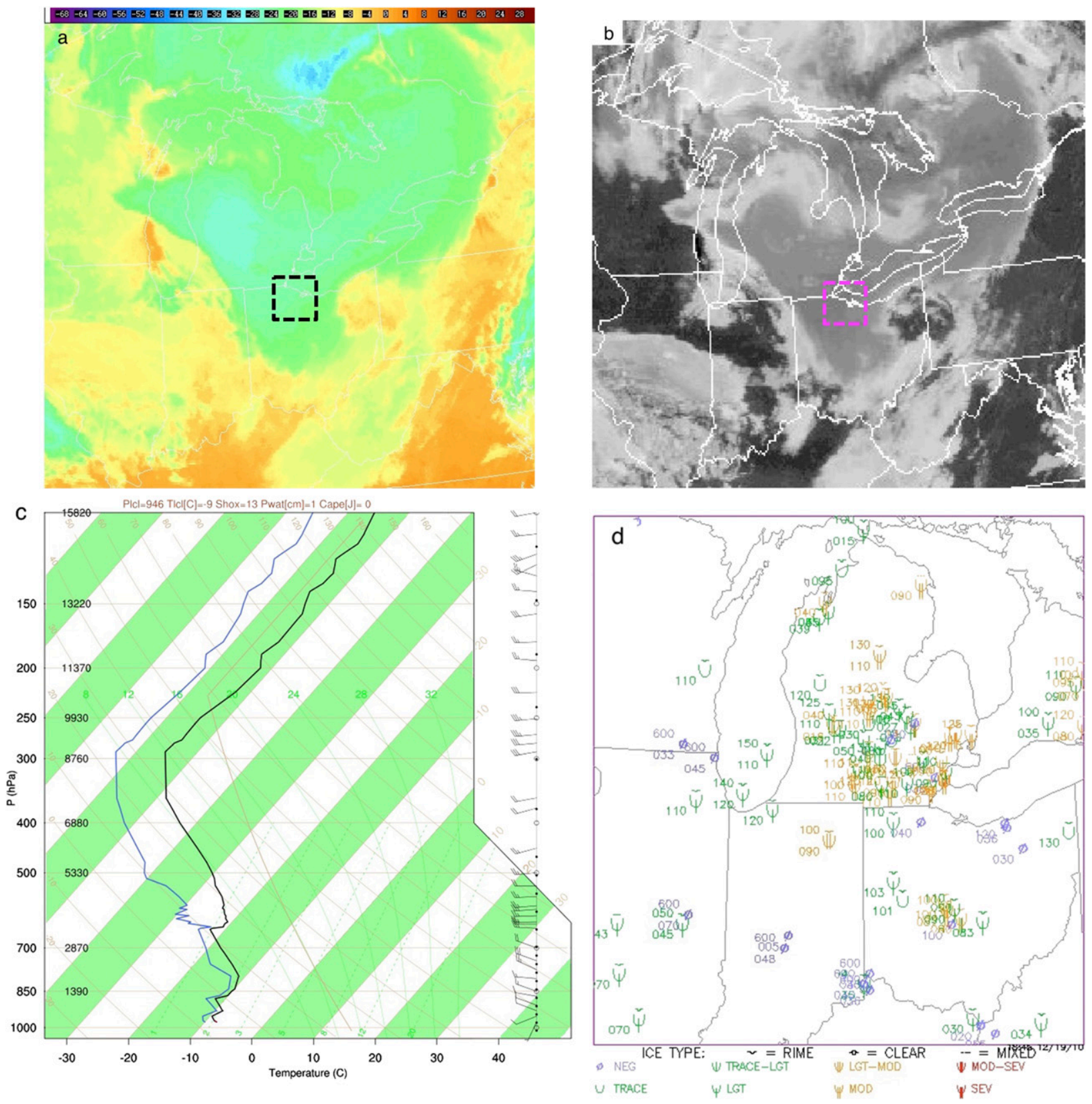

FIG. 8. (a) Longwave infrared and (b) shortwave infrared reflectance imagery for 1545 UTC, (c) Detroit, MI (KDTX), sounding for 1200 UTC showing the vertical structure, and (d) pilot reports of icing for 1052-1836 UTC. Infrared imagery shows the cold cloud tops, while darker areas (higher values) indicate relatively large particles in shortwave infrared reflectance imagery. Dashed boxes show the location of sampling during the test flight.

low-level inversions were more common, icing layers sampled above the near-surface inversion layer tended to have lower drop concentrations $(\mathrm{CONC}<50)$ and larger MVDs $(25-35 \mu \mathrm{m})$, possibly due to reduced aerosol loading. Similar anecdotal tendencies were found with snow cover over other parts of North America, especially when it was sustained for long periods, perhaps cutting off some $\mathrm{CCN}$ and IN sources.
Certification aircraft also sampled maritime environments and those are briefly discussed here to provide context. Even when clouds were found within the wellmixed BL, low drop concentrations and large MVDs $(25-40 \mu \mathrm{m})$ were commonly observed along the coasts of Oregon, Washington, and southeastern Alaska, especially with onshore flow (as in Ikeda et al. 2007). However, it is interesting to note that on a few occasions 
of onshore flow with strong instability, clouds sampled west of the Cascades were found to have relatively small MVDs of $15-25 \mu \mathrm{m}$. It may be that CONC values rose rapidly over a very short time and distance due to BL mixing.

Reversing this scenario, one wintertime flight into boundary layer stratocumulus over the Atlantic Ocean, $\sim 250 \mathrm{~km}$ southeast of New York City featured variable LWC $\left(0.2-0.7 \mathrm{~g} \mathrm{~m}^{-3}\right)$, but relatively small MVD $(15-20 \mu \mathrm{m})$. These clouds developed in strong cold-air advection as cold continental air from the East Coast caused stratocumulus to develop over the Atlantic. As expected, this cloud had small drop sizes, implying that high CONC values were maintained, despite the air passing over open ocean for $\sim 4 \mathrm{~h}$. Similar tendencies associated with airmass origin have been reported within stratocumulus clouds off the coast of Europe by Martin et al. (1994).

Manufacturers sometimes need to test in clouds with MVDs toward the large end of the certification envelope (15-40 $\mu \mathrm{m}$; FAA 1999). When seeking clouds with MVDs of $30-40 \mu \mathrm{m}$, it is inevitable that SLD will eventually be encountered. This was the case for one January event near Spokane, Washington. Both the Spokane (KOTX) and upstream Quillayute (KUIL) soundings had strong low-level stability across Washington, capped by a roughly moist-adiabatic subfreezing layer, in which the aircraft flew (Fig. 9). Though cold clouds were associated with snow reaching the surface to the south of Spokane, a dry layer to the north kept the clouds of interest from being seeded from above. At the same time, the low-level stability appears to have allowed maritime air to advect well inland at midlevels without contamination by BL air from below, making it a prime candidate for enhanced drop size. This proved to be the case, as the aircraft twice encountered 0.2-0.4 $\mathrm{g} \mathrm{m}^{-3}$ LWCs and 35-50 $\mu \mathrm{m}$ MVDs at $-12^{\circ} \mathrm{C}$ near $\sim 4000 \mathrm{~m}$. SLD was observed and the pilots reported moderate mixed icing.

\section{Putting past icing events into context}

It is interesting to consider some well-documented icing events from the literature and some well-known icing accidents and incidents in the context of this study, providing some insight regarding the environments in which they occurred.

\section{a. Icing research flight programs}

During the Winter Icing and Storms Program (Rasmussen et al. 1992), a strong cold front passed through Denver on 13 February 1990, followed by upslope flow that produced SLW, SLD, and snow.
The front stalled to the south of Denver and southerly winds subsequently developed over the frontal inversion, providing upglide in a slightly stable layer. The University of Wyoming King Air (UWKA) made a vertical profile into the drizzle-producing clouds, finding two liquid cloud layers, with the upper layer having LWCs up to $0.35 \mathrm{~g} \mathrm{~m}^{-3}$, supercooled drizzle and no ice crystals (Rasmussen et al. 1995). The authors demonstrated drizzle production in the upper layer using a droplet growth model and an assumed CONC of $100 \mathrm{~cm}^{-3}$. Given the LWC observed in this layer and the fact that it produced SLD, Fig. 3 suggests that the assumed CONC was reasonable.

Another UWKA flight was initiated just as clouds began to form northwest of Denver on 27 February 1990. The clouds formed after the passage of a secondary cold front and their upper portion featured LWC of $0.4-0.5 \mathrm{~g} \mathrm{~m}^{-3}$ and CONC of $100-150 \mathrm{~cm}^{-3}$ (FSSP and 1-DC probes combined; Politovich and Bernstein 1995). Although this combination falls well within the largedrop domain, MVDs were only $10-13 \mu \mathrm{m}$ and large drops were not observed during this initial encounter. Less than an hour later, the aircraft found lower LWCs $\left(0.15-0.30 \mathrm{~g} \mathrm{~m}^{-3}\right)$ and $\mathrm{CONC}\left(<25 \mathrm{~cm}^{-3}\right)$, as well as larger MVDs (20-25 $\mu \mathrm{m})$ and SLD after exiting some snow showers. Farther away from the snow showers, larger LWC $\left(\sim 0.6 \mathrm{~g} \mathrm{~m}^{-3}\right)$ and higher CONC $\left(100-150 \mathrm{~cm}^{-3}\right)$ were observed. Most of the LWC increase was at the small end of the DSD, causing MVDs to fall to $\sim 15 \mu \mathrm{m}$, though large drops were still present. Although all three environments fell within the "large drop" domain of Fig. 3, not all of the DSDs included SLD.

Hoffmann and Demmel (1992) documented three SLD cases over southern Germany that resulted in "severe" effects on DLR's Dornier-28 (DO-28) research aircraft. SLD was noted near the cloud tops and rough ice formed aft of the ice protection that caused significant (sometimes rapid) airspeed losses in all three cases. Their single-layer, all-liquid case " $a$ " is particularly interesting. In it, $T$ increased gradually with height for several hundred meters, then increased more sharply toward cloud top (Fig. 10), rather than only within the dry air above cloud top, as is commonly observed. Hoffmann and Demmel (1992) noted LWC, CONC, and MVD were $0.39 \mathrm{~g} \mathrm{~m}^{-3}, 179 \mathrm{~cm}^{-3}$, and $23 \mu \mathrm{m}$ beneath the very stable cloud-top zone. Though not mentioned in their paper, LWC of $\sim 0.28 \mathrm{~g} \mathrm{~m}^{-3}$ and MVD of $\sim 23 \mu \mathrm{m}$ were observed within the stronger part of the inversion, just below cloud top. This drizzle generation zone near cloud top is remarkably similar to the "SLD overhang" structure found by the authors in sounding data for numerous other FZDZ events over continental parts of North America. Such stable SLD 

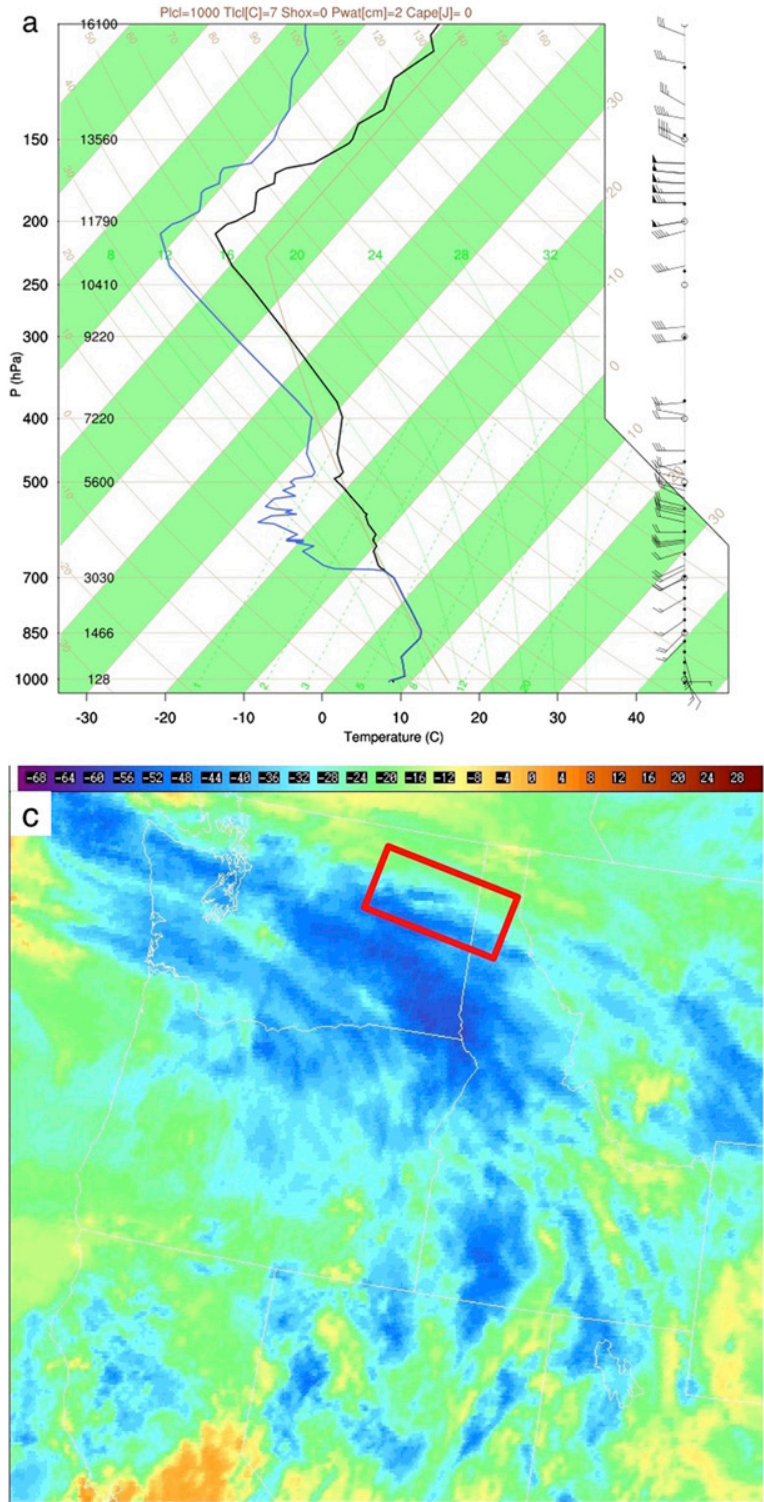
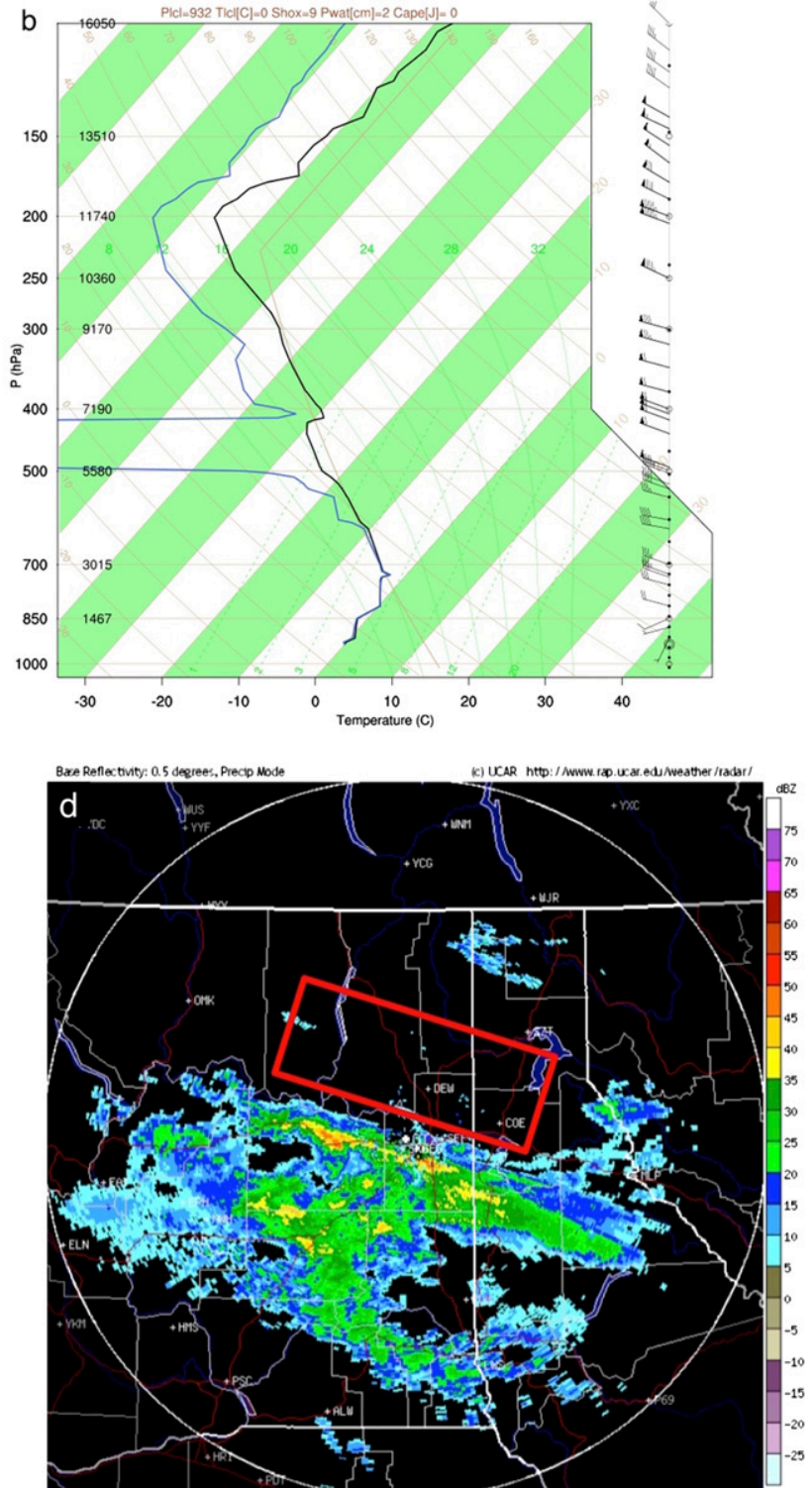

FIG. 9. (a) Quillayute (KUIL) and (b) Spokane, WA (KOTX), soundings for 1200 UTC. Some bad dewpoint data was present in the KOTX sounding between 500 and $400 \mathrm{mb}$. Temperature data also may have been somewhat compromised at those levels. (c) GOES infrared satellite image for 1500 UTC and (d) Spokane NEXRAD $0.5^{\circ}$ reflectivity for 1456 UTC. The area of sampling is enclosed by red boxes on the satellite and radar imagery.

generation zones may be associated with gentle overrunning, as in the 13 February 1990 case discussed above, and/or may be associated with isobaric mixing, as described by Korolev and Isaac (2000).

Additional flights over southern Germany in 1997 were examined by Hauf and Schroeder (2006), this time within stratocumulus that featured $\sim 200$-m overshooting turrets. Embedded within a background LWC of $0.15 \mathrm{~g} \mathrm{~m}^{-3}$, LWC nearly doubled and SLD (mixed with crystals) was observed in $100-300 \mathrm{~m}$ wide patches immediately beneath the turrets. The authors noted that "the occurrence of SLD seems to be correlated with the LWC in the cloud drop mode." CONC was not reported in their paper, but several shallow stable zones were present in radiosonde and aircraft temperature profiles, indicating potential for isolation from the local BL. In the context of Fig. 3, their observations hint that localized instability may have caused LWC enhancement that pushed the LWC:CONC ratio into the largedrop domain. This assumes that CONC values were fairly similar from the top of the stratocumulus deck into the turrets, which may or may not have been the 

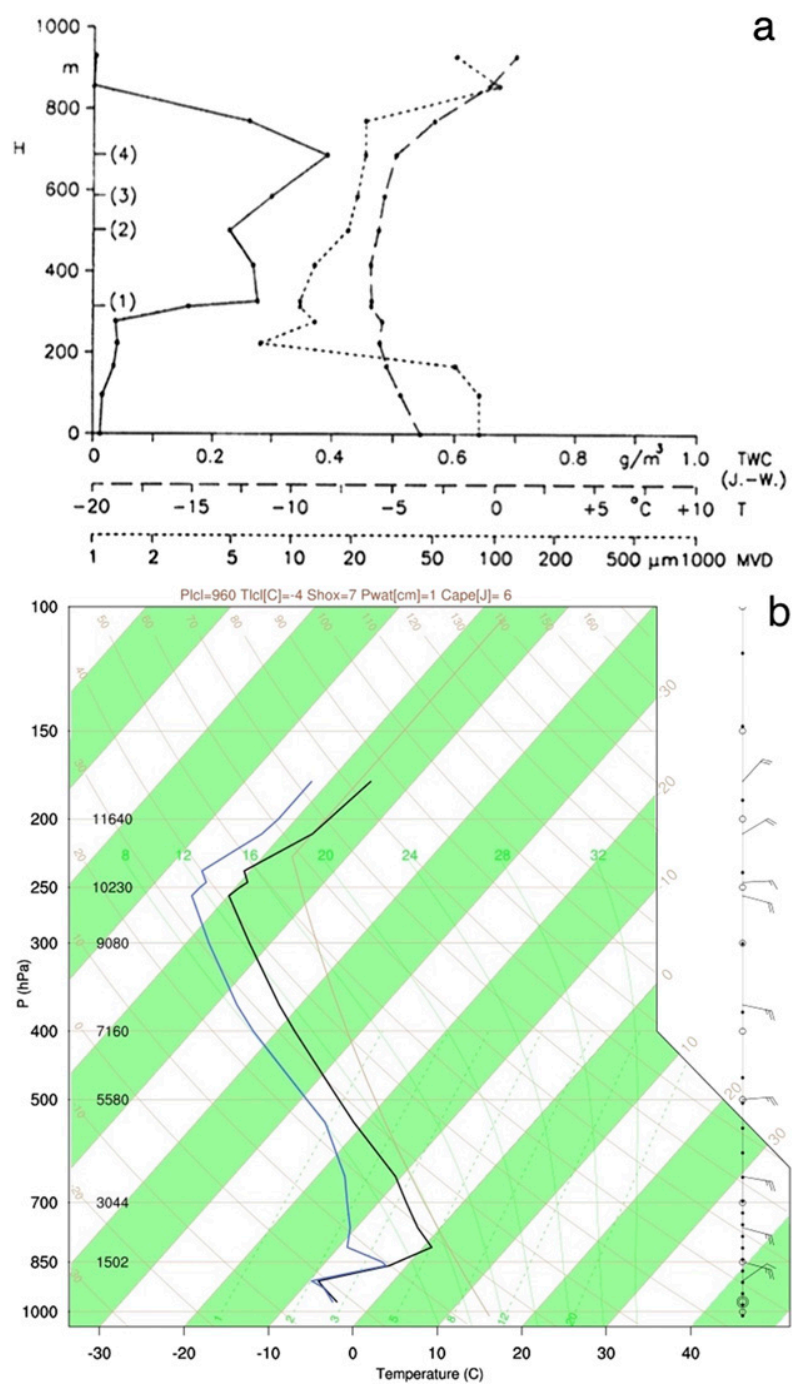

FIG. 10. (a) Vertical profiles of Johnson-Williams probe TWC (LWC in this all-water case; solid line), $T$ (dashed line), and MVD (dotted line) from the DLR Dornier-228 research aircraft for an SLD event over southern Germany, from Hoffmann and Demmel (1992). (b) Sounding from Munich, Germany, near the location and time of the flight. Both are from 1200 UTC 19 Jan 1987.

case. It is also unknown how consistent cloud bases were. Local variability in cloud-base temperature and stability within the stratocumulus deck could have played a role.

Cober et al. (2001) detailed several SLD environments sampled by the NRC Convair-580 during the Canadian Freezing Drizzle Experiment (CFDE-I and CFDE-III). The authors contrasted the nonclassical SLD sampled in maritime (Saint Johns) and continental (Ottawa) environments, finding that the continental SLD cases tended to have larger LWC and CONC, while MVD and LWC in drops $>50 \mu \mathrm{m}$ were generally smaller. Placing the Cober et al. (2001) events into the context of Fig. 3 is difficult because their Table 2 only provided median and maximum values of LWC and CONC for the encounters. Still, it is interesting to note that when using the median LWC and CONC values for SLW-dominated events, all 6 maritime and 2 of the 3 continental SLD events would have either fallen into Fig. 3's large-drop domain or slightly above the line. Significant LWC and/or CONC variability was noted in most of their cases, and most were associated with warm fronts or low pressure regions.

\section{b. Icing-related accidents and incidents}

On 31 October 1994, one of the most well-known icing accidents occurred when an ATR-72 went into a hold in SLD over Roselawn, Indiana, and subsequently crashed, killing all 68 people on board (NTSB 1996; Marwitz et al. 1997). The aircraft was flying ahead of a warm front, in warm-air advection just above the frontal zone. The holding area was located in breaks along the edges of precipitation, in a patch of relatively warm cloud tops $\left(-10^{\circ}\right.$ to $\left.-15^{\circ} \mathrm{C}\right)$, with indications of layering, and higher, colder clouds moving off to the north (Fig. 11). Soundings taken to the east of the upper low featured strong stable layers, with variable stability and saturated air above low-level stable layers.

On 16 February 2005, a Cessna Citation crashed after encountering SLD during descent into Pueblo, Colorado (KPUB; NTSB 2007). Following the passage and subsequent stalling of a cold front to the south overnight, morning reports from the KPUB ASOS included low ceilings and "mist" (a common misreport during FZDZ events; Landolt et al. 2014), while nearby stations and volunteer observers reported FZDZ and some light snow. Radar data indicated smooth-textured, low reflectivity $(<0 \mathrm{~dB} Z)$ close to the radar (as in Ikeda et al. 2009), while satellite imagery had relatively warm cloud tops $\left(-10^{\circ}\right.$ to $\left.-15^{\circ} \mathrm{C}\right)$ beneath a broken, higher layer (Fig. 12). Sounding data were not available over KPUB, but the Denver (KDEN) sounding had a post-cold-frontal boundary layer with easterly flow capped by a shallow stable layer, then well-mixed clouds up to $-11^{\circ} \mathrm{C}$ above. Light, southerly winds were present in the upper layer at KDEN and wind profiles from the Pueblo NEXRAD indicated $10 \mathrm{~m} \mathrm{~s}^{-1}$ southerlies overrunning the stationary front at KPUB (not shown). This is another example of SLD production in a liquid cloud layer isolated from the boundary layer possibly contributing to an accident.

At 2240 UTC 2 January 2006, a Saab-340 climbing out of San Luis Obispo, California, encountered SLD icing at $\sim 3500 \mathrm{~m}$ near Santa Maria, very close to the Pacific coast. The aircraft subsequently departed from controlled flight and rapidly lost $\sim 1500 \mathrm{~m}$ of altitude 

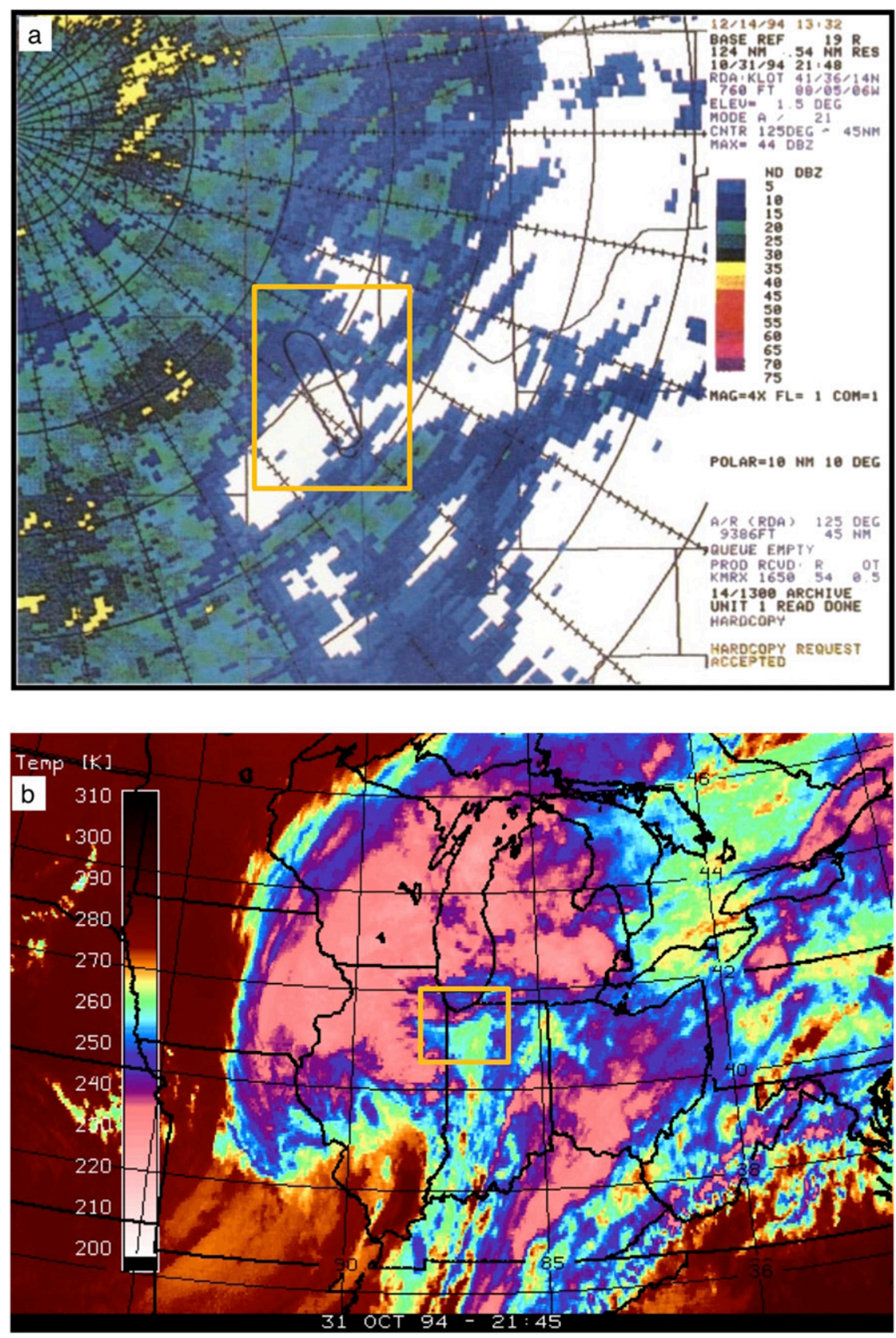

FIG. 11. (a) Lockport, IL (KLOT), NEXRAD $1.5^{\circ}$ reflectivity scan from 2148 UTC 31 Oct 1994, with the holding track of American Eagle Flight 4184 superimposed (black oval). Reflectivity color table is shown at the right. The radar beam was indicated to be $\sim 2900 \mathrm{~m}$ at the location of the aircraft. [From NTSB (1996).] (b) GOES infrared satellite imagery from 2145 UTC (temperature scale in K shown at the left). The area of the hold is enclosed by tan boxes on the radar and satellite imagery.

before recovering (NTSB 2006). Showers and variable CTTs were present. A sounding from nearby Vandenberg Air Force Base indicated deep onshore flow, with 40 -kt $\left(1 \mathrm{kt} \approx 0.51 \mathrm{~m} \mathrm{~s}^{-1}\right)$ westerlies at $\sim 3000 \mathrm{~m}$, and saturated (or nearly saturated) conditions from just above the surface to $4475 \mathrm{~m}(575 \mathrm{mb})$, where the
$T$ was $-17^{\circ} \mathrm{C}$ (Fig. 13). Lapse rates were nearly moist adiabatic in the upper portion of the clouds, but more variable below; $T$ was near $-10^{\circ} \mathrm{C}$ at level of flight where the aircraft lost control. The combination of unstable, maritime cloud isolated from inland sources of $\mathrm{CCN}$ and IN, with warm enough cloud tops to 

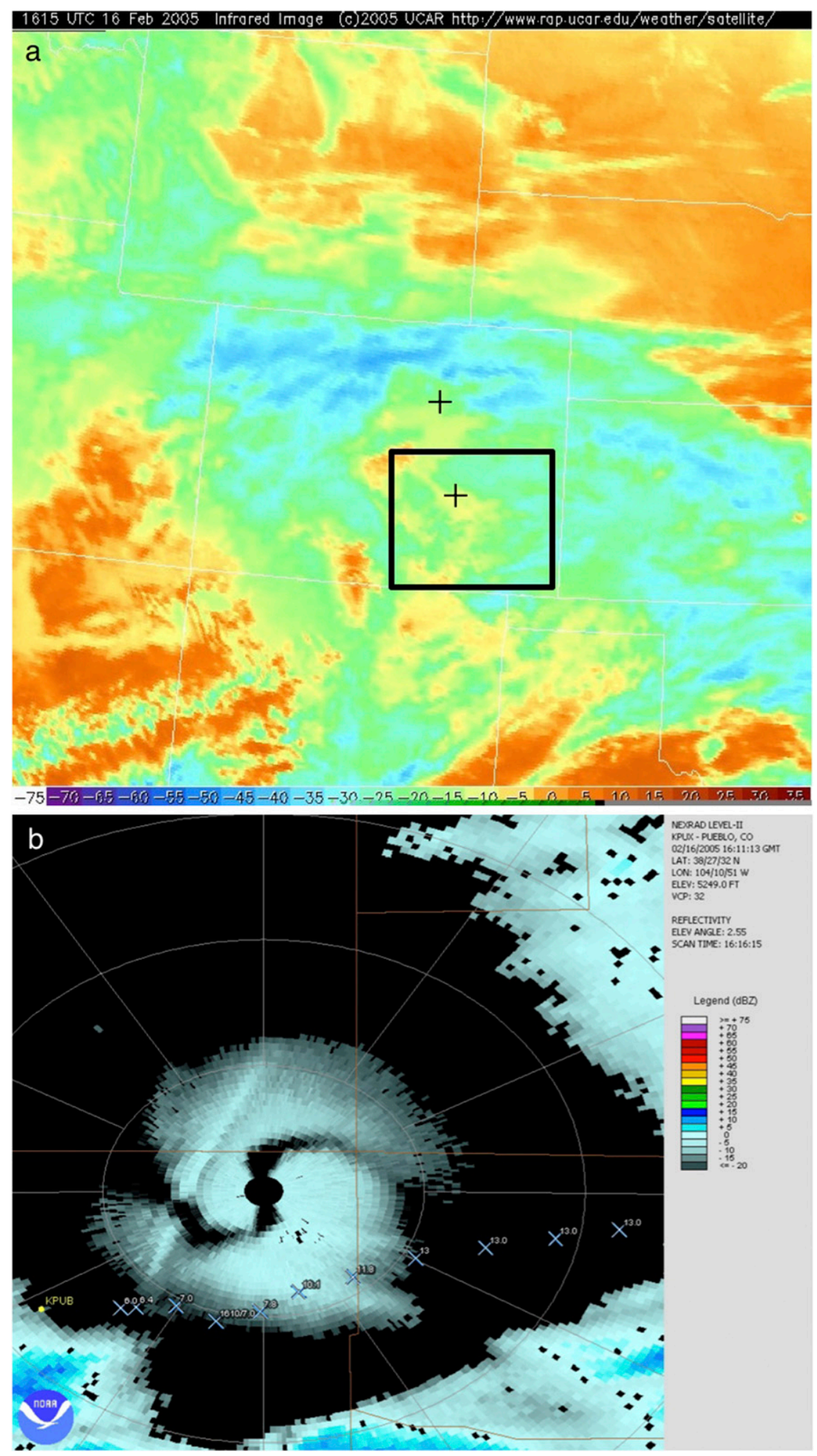

FIG. 12. (a) GOES infrared satellite imagery for 1615 UTC 16 Feb 2005, with the area of interest enclosed by a box. The locations of KDEN and KPUB are each indicated with a plus (+) symbol. (b) Pueblo, CO (KPUX), NEXRAD $2.5^{\circ}$ reflectivity scan from 1611 UTC, with the track (crosses) and altitudes $(\times 1000 \mathrm{ft})$ of aircraft N500AT superimposed. Reflectivity color table is shown at the right. 


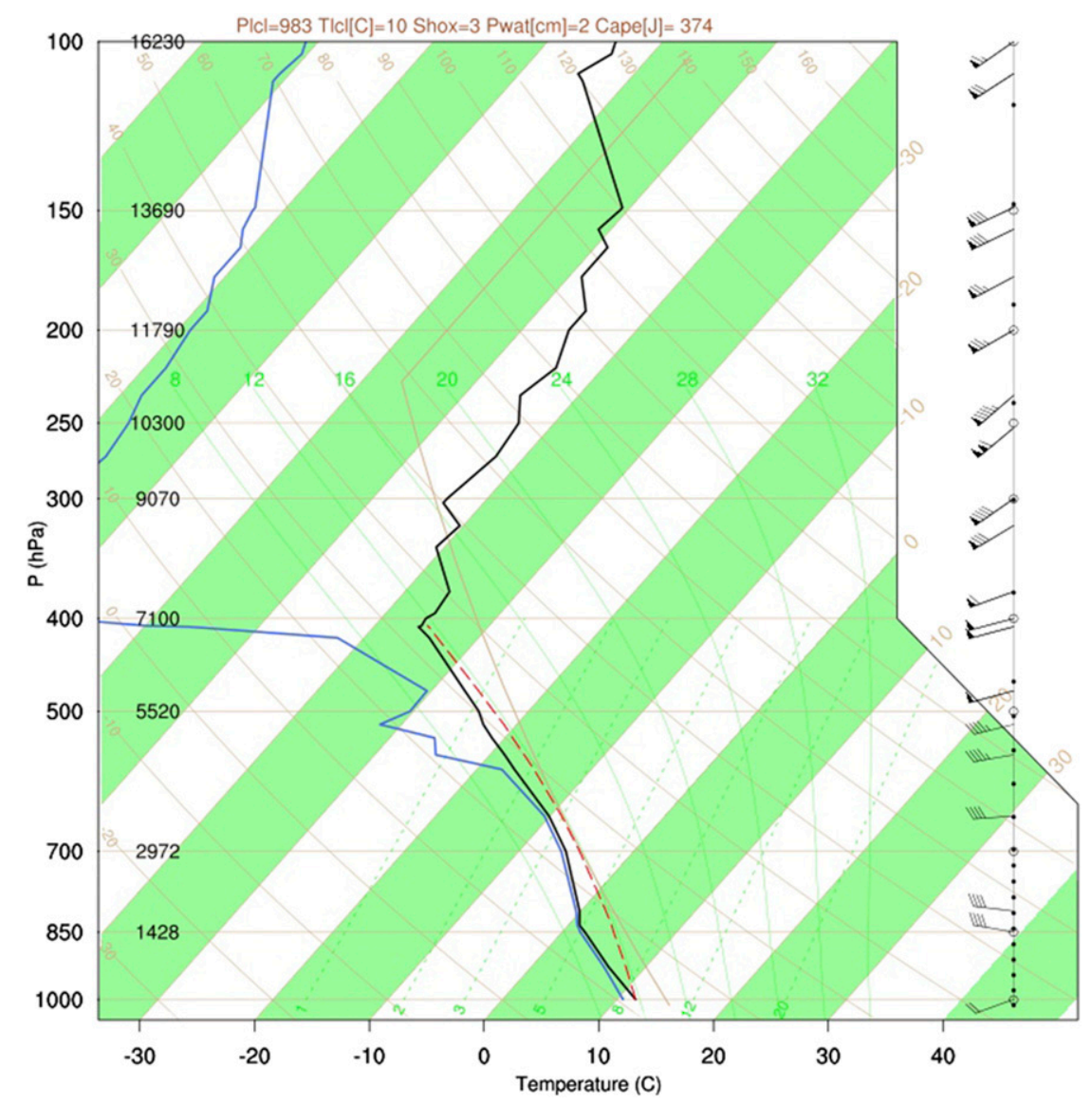

FIG. 13. Balloon-borne sounding from Vandenberg Air Force Base, valid at 0000 UTC3 Jan 2006.

support the presence of supercooled liquid water, was ideal for SLD production.

On 14 September 2005, an ATR-42 encountered SLD during climb through $3000 \mathrm{~m}$ at $-10^{\circ} \mathrm{C}$ over southern Norway. The pilots reported "large drops splattering on the windshield," side window icing (commonly observed during flight in SLD) and extremely rapid ice buildup. As the aircraft continued to $4400 \mathrm{~m}$, airspeed decreased, climb capability deteriorated, and the autopilot disconnected. After losing control of the aircraft twice and dropping $\sim 500 \mathrm{~m}$, control of the aircraft was regained between two cloud layers, where icing was not present (Accident Investigation Board Norway 2009). This event occurred in the remnants of Hurricane Maria. Onshore winds from the Norwegian Sea brought unusually high moisture contents, layered clouds with $-12^{\circ}$ to $-17^{\circ} \mathrm{C}$ tops that were slowly cooling, and some showers to the area (Fig. 14). A sounding taken nearby $\sim 6 \mathrm{~h}$ before the event featured deep, cold-topped, heavily precipitating clouds with variable stability, including weak stability near the surface and near $3000-4000 \mathrm{~m}$. Dry air moved into southern Norway above $\sim 500 \mathrm{mb}$, and the heavy precipitation ended there about $1.5 \mathrm{~h}$ before the incident. A WRF Model simulation of the event using the Thompson et al. (2008) microphysics featured high LWC, abundant SLD (supercooled "rain water") and very little snow (ice water) in the area of flight (Kristjánsson et al. 2010). This near disaster is another example of SLD forming in isolated, unstable maritime air with light showers and relatively warm cloud tops.

While LWC and CONC values were not available for these incidents and accidents, each had numerous environmental elements that were commonly found in SLD events documented by the research and certification aircraft in the previous sections.

\section{Retrospective on the climatology of FZDZ}

This study may also shed some light on the diurnal and geographic tendencies noted in climatologies of FZDZ. Cortinas et al. (2004) found that FZDZ frequency gradually increased from dusk to dawn, followed by a rapid decrease in the morning. This diurnal swing may be associated with the nocturnal cloud-top radiative 

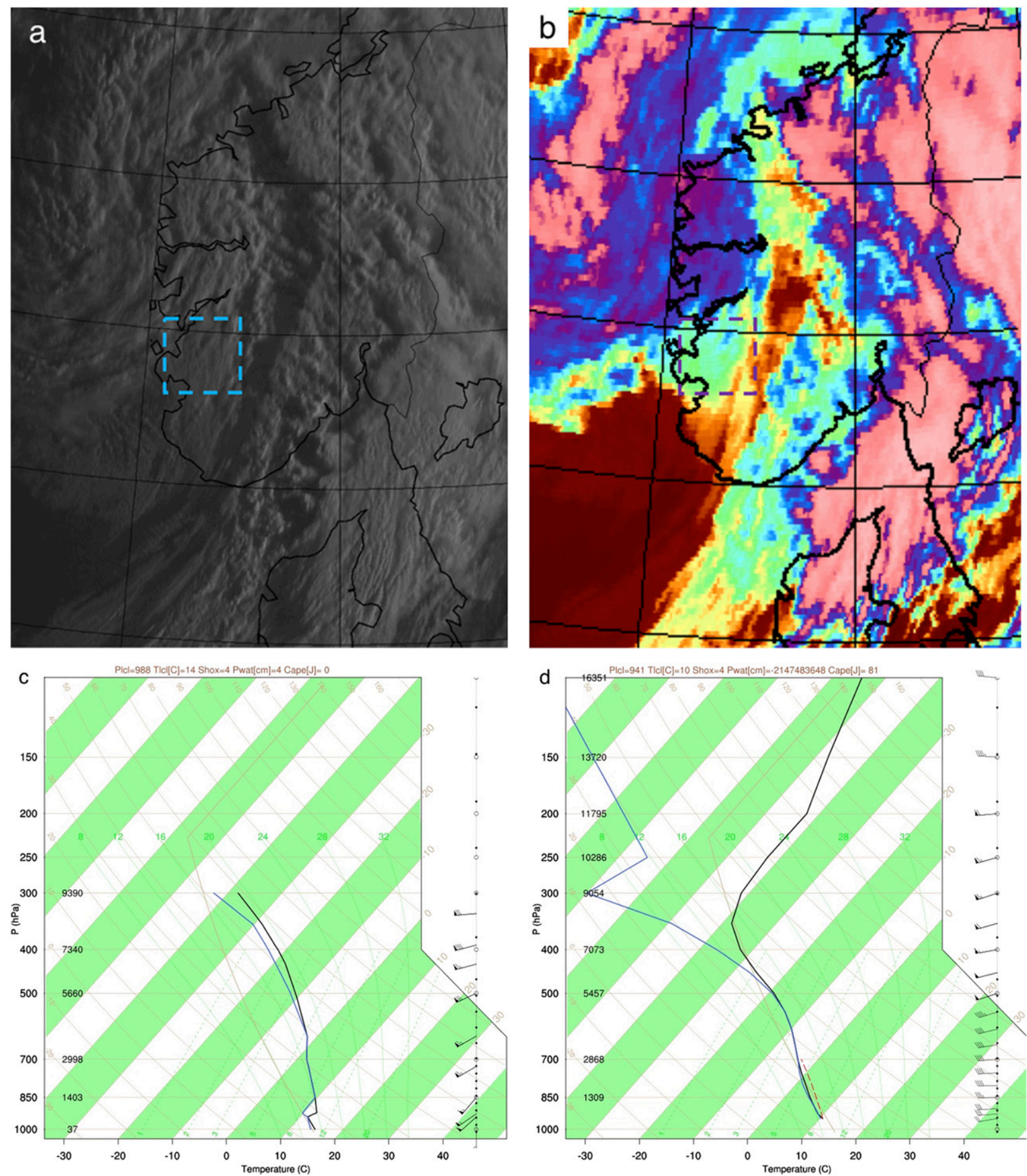

FIG. 14. Meteosat (a) visible (0530 UTC) and (b) infrared (0515 UTC) satellite imagery, (c) balloon-borne sounding from Stavanger, Norway, valid at 0000 UTC and (d) GFS 6-h forecast sounding in the incident area valid at 0600 UTC 14 Sep 2005. The area of the incident is enclosed by the dashed boxes on satellite imagery. The 0530 UTC visible image was used due to insufficient light and shadowing on the 0515 UTC visible image.

cooling combined with the development and intensification of surface-based stable layers. Radiative cooling can destabilize preexisting supercooled cloud tops and enhance LWC there (Harrington et al. 2000; Rasmussen et al. 2002). However, newly developed nocturnal inversions are not likely to significantly affect drop concentrations within those clouds. Instead, as instability develops aloft, developing surface stability may inhibit 
the further addition of $\mathrm{CCN}$ and IN from surface sources, presumably keeping CONC values relatively constant. As cloud-top LWCs increase, LWC:CONC ratios would move gradually to the right in Fig. 3. Thus, clouds with LWC:CONC ratios close to transition zone may cross it in short order, while others may require more time (further cooling) to allow SLD production to initiate. This may explain the gradual increase in FZDZ frequency from dusk to dawn. One must also bear in mind that time is required for the FZDZ developing near cloud top to populate the cloud and fall to the surface. Soon after sunrise, cloud-top cooling should cease while surface inversions weaken, reversing the trend and perhaps explaining the marked decline in FZDZ frequency in the morning.

Geographic tendencies in SLD frequencies aloft found by Bernstein et al. (2007) appear to match the exposure of high-frequency areas to the SLD-friendly environments discussed here. During the cool season, maritime air masses and frequent storm activity impact the Pacific Northwest and Canadian Maritimes, while inland areas such as the Midwest and Great Lakes frequently experience overrunning and warm-air advection. High FZDZ frequency and particularly strong diurnal swings in FZDZ frequency in places like the Columbia River basin are more difficult to explain, but this study implies that they may be driven by a combination of inland advection of maritime air (as in the Spokane case) and nocturnal effects on long-lived, continental stratus/stratocumulus (Whiteman et al. 2001; Cortinas et al. 2004; Miller et al. 1999). The latter effect can occur anywhere and may help to explain other localized FZDZ maxima noted in climatological studies.

\section{Discussion and conclusions}

While the relative lack of $\mathrm{CCN}$ in maritime clouds has long been known to be conducive to the production of large drops, this study demonstrates that synoptic and mesoscale phenomena that drive a high LWC:CONC ratio provide a good indication of whether large-drop icing should be expected in continental clouds. BLrooted, continental clouds tended to have high concentrations of small drops, and high LWC appears to be necessary to force a sufficient ratio to initiate SLD. In contrast, continental clouds isolated from the BL due to low-level stability typically had low drop concentrations, possibly because they were cut off from ground-level aerosol sources, allowing them to more readily produce SLD. Such environments were common when elevated layers of instability or mild stability and lift occurred above stable layers. In most cases, these clouds had relatively warm tops (usually $>-12^{\circ} \mathrm{C}$ ) that promote liquid, rather than ice production. Vertical stability and cloud layering, certain types of synoptic- and mesoscale forcing, residence time and snow cover may also play a significant role.

Forecasters can look for these features to help identify SLD-prone continental situations, but other features have also proven to be useful. Surface observations of FZDZ and DZ provide obvious clues to the presence of large drops above (Bernstein 2001; McDonough and Bernstein 2004). Satellite-based infrared derivatives provide additional information about drop size in the highest cloud layer when that layer is dominated by liquid (e.g., Lee et al. 1997; Smith et al. 2012). Radar data provide insights via (i) smooth areas of low reflectivity values (Ikeda et al. 2009), (ii) polarization signals like low ZDR (Vivekanandan et al. 1999; Serke et al. 2015, 2017), and (iii) showery areas where SLD can sometimes be found in gaps between significant echoes or within showers driven by slightly overshooting tops, especially when SLD-conducive vertical structures are present. Advanced model microphysics schemes can now directly predict CONC based on full aerosolcoupled models (Thompson and Eidhammer 2014). Such an approach has good potential, but its output should be considered carefully in the context of other information.

It is important to recognize that the results of this study provide tendencies, based on hundreds of research and certification flights over more than 20 years. There certainly are exceptions to the relationship between LWC:CONC ratio and the presence of SLD, some of which have been noted herein. When trying to determine which drop size domain a given event may fall within, it is critical to consider the full spectrum of factors described in this study in concert. It is not as simple as saying "there are warm cloud tops in a saturated layer of instability above an inversion, so expect SLD." It is best to look for multiple clues in both observational and forecast data, combining them to get a notion of drop size. Short-term nowcasts can benefit from recent observations, pattern movement and feature evolution, but longer-range forecasts have relatively little SLD-relevant information to work with. Beyond output from explicit microphysics schemes, forecasts of temperature and moisture profiles, dynamics (often subtle for SLD), and 3D moisture patterns can be used in conjunction with geographical and diurnal tendencies.

Automated icing algorithms such as the Current Icing Product (CIP; Bernstein et al. 2005), Forecast Icing Product (FIP; McDonough et al. 2004), System of Icing Geographic Identification in Meteorology for Aviation (SIGMA; LeBot 2004), and Advanced Diagnosis and Warning System for Aircraft Icing Environments (ADWICE; Tafferner et al. 2003) ingest information 
from data sources described above, providing ample opportunity to identify SLD-related signatures. Recently, CIP and FIP began using vertical structure to enhance their ability to assess the potential for SLD (McDonough et al. 2008). Their SLD fields might be improved further by combining the presence, strength and longevity of this structure with the expected LWC already calculated as part of the CIP and FIP icing severity algorithms (Bernstein et al. 2006b; Wolff et al. 2009). Diagnoses and short-term forecasts of icing, SLD, and mesoscale variability thereof, can be further enhanced through expanding the use of the satellite-, radar-, surface-, and model-based features described above.

Acknowledgments. The authors would like to express our sincere thanks to the crews of the NASA-Glenn Twin Otter, the NRC Convair-580, and the University of Wyoming King Air, who safely and thoroughly sampled so many icing events. We would also like to thank the pilots and engineers from the anonymous aircraft manufacturers that generously shared data from their certification flights; Lyle Lilie of Science Engineering Associates for help with flight data; Rick Kohrs of Space Science Engineering Center for satellite imagery; Ian Wittmeyer of FlightCast Inc. for help with graphics; Greg Thompson and Marcia Politovich (retired) of NCAR; Alexei Korolev, Walter Strapp (retired), Stewart Cober, and George Isaac (retired) of Environment and Climate Change Canada; and Richard Ranaudo (retired) of NASA GRC and the University of Tennessee for insightful discussions over the many years that it took to complete this work.

\section{REFERENCES}

Accident Investigation Board Norway, 2009: Report on the serious incident over glacier Folgefonna, Norway on 14 September 2005 with ATR 42-320, LN-FAO, operated by Coast Air AS. AIBN Rep. SL 2009/02, 71 pp., https://www.aibn.no/Aviation/ Reports/2009-02-eng.

Bernstein, B. C., 2000: Regional and local influences on freezing drizzle, freezing rain, and ice pellet events. Wea. Forecasting, 15, 485-508, https://doi.org/10.1175/1520-0434(2000)015<0485: RALIOF $>2.0 . \mathrm{CO} ; 2$.

_ 2001: Evaluation of NCAR Icing/SLD forecasts, tools and techniques used during the 1998 NASA SLD flight season. NASA CR-2001-210954, 52 pp., https://ntrs.nasa.gov/archive/ nasa/casi.ntrs.nasa.gov/20010097719.pdf.

— , and R. Flemming, 2007: Certification of the Sikorsky S-92A Helicopter Ice Protection System: Meteorological aspects of tanker tests and natural icing flights. SAE Trans., 116, 664-671.

, T. Omeron, M. Politovich, and F. McDonough, 1998: Surface weather features associated with freezing precipitation and severe in-flight aircraft icing. Atmos. Res., 46, 57-74, https:// doi.org/10.1016/S0169-8095(97)00051-3.
—, F. McDonough, M. K. Politovich, B. G. Brown, T. P. Ratvasky, D. R. Miller, C. A. Wolff, and G. Cunning, 2005: Current Icing Potential (CIP): Algorithm description and comparison with aircraft observations. J. Appl. Meteor., 44 969-986, https://doi.org/10.1175/JAM2246.1.

- W. Campo, L. Algodoal, F. Bottino, L. Lillie, and A. Henriques, 2006a: The Embraer-170 and -190 Natural Icing Flight Campaigns: Keys to success. American Institute of Aeronautics and Astronautics, 2006-264, 21 pp.

—, F. McDonough, C. A. Wolff, M. K. Politovich, G. Cunning, S. Mueller, and S. Zednik, 2006b: The new CIP icing severity product. 12th Conf. on Aviation, Range and Aerospace Meteorology, Atlanta, GA, Amer. Meteor. Soc., P9.5, http:// ams.confex.com/ams/pdfpapers/102273.pdf.

— C. A. Wolff, and F. McDonough, 2007: An inferred climatology of icing conditions aloft, including supercooled large drops. Part I: Canada and the continental United States. J. Appl. Meteor. Climatol., 46, 1857-1878, https://doi.org/ 10.1175/2007JAMC1607.1.

_ F. McDonough, and C. A. Wolff, 2011: A regional comparison of icing conditions in boundary layer clouds. Int. Conf. on Aircraft and Engine Icing and Ground Deicing, Chicago, IL, SAE, 2011-38-0021, http://papers.sae.org/2011-38-0021.

Biter, C. J., J. E. Dye, D. Huffman, and W. D. King, 1987: The dropsize response of the CSIRO liquid water probe. J. Atmos. Oceanic Technol., 4, 359-367, https://doi.org/10.1175/15200426(1987)004<0359:TDSROT>2.0.CO;2.

Bocchieri, J. R., 1980: The objective use of upper air soundings to specify precipitation type. Mon. Wea. Rev., 108, 596-603, https://doi.org/10.1175/1520-0493(1980)108<0596:TOUOUA $>$ 2.0.CO;2.

Cober, S. G., and G. A. Isaac, 2006: Estimating maximum aircraft icing environments using a large data base of in-situ observations. AIAA 44th Aerospace Sciences Meeting and Exhibit, Reno, NV, AIAA, AIAA 2006-0266, https://doi.org/10.2514/6.2006-266.

$\longrightarrow$, and - 2012: Characterization of aircraft icing environments with supercooled large drops for application to commercial aircraft certification. J. Appl. Meteor., 51, 265-284, https://doi.org/10.1175/JAMC-D-11-022.1.

,-- , and J. W. Strapp, 2001: Characterizations of aircraft icing environments that include supercooled large drops. J. Appl. Meteor., 40, 1984-2002, https://doi.org/10.1175/15200450(2001)040<1984:COAIET > 2.0.CO;2.

Cortinas, J. V., B. C. Bernstein, C. C. Robbins, and J. W. Strapp, 2004: An analysis of freezing rain, freezing drizzle, and ice pellets across the United States and Canada: 1976-90. Wea. Forecasting, 19, 377-390, https://doi.org/10.1175/15200434(2004)019<0377:AAOFRF $>2.0 . \mathrm{CO} ; 2$.

DiVito, S., and J. T. Riley, 2017: An overview of the Federal Aviation Administration (FAA) Terminal Area Icing Weather Information for NextGen (TAIWIN) Project. 18th Conf. on Aviation, Range and Aerospace, Seattle, WA, Amer. Meteor. Soc., https://ams.confex.com/ams/97Annual/ webprogram/Paper314380.html.

FAA, 1999: Appendix C. Airworthiness Standard: Transport Category Airplanes, Part 25, Aeronautics and Space, Title 14, U.S. Code of Federal Regulations, National Archives and Records Administration, 536-543.

_- 2015: Airplane and Engine Certification Requirements in Supercooled Large Drop, Mixed Phase and Ice Crystal Icing Conditions; Final Rule. Parts 25 and 33, Aeronautics and Space, Title 14, U.S. Code of Federal Regulations, National Archives and Records Administration, 34 pp. 
Feingold, G., and A. J. Heymsfield, 1992: Parameterizations of condensational growth of droplets for use in general circulation models. J. Atmos. Sci., 49, 2325-2342, https://doi.org/ 10.1175/1520-0469(1992)049<2325:POCGOD > 2.0.CO;2.

Geresdi, I., R. Rasmussen, W. Grabowski, and B. Bernstein, 2005: Sensitivity of freezing drizzle formation in stably stratified clouds to ice processes. Meteor. Atmos. Phys., 88, 91-105, https://doi.org/10.1007/s00703-003-0048-5.

Green, S. D., 2006: A study of U.S. inflight icing accidents and incidents, 1978 to 2002. 44th AIAA Aerospace Sciences Meeting and Exhibit, Reno, NV, AIAA, AIAA 2006-82, https://doi.org/10.2514/6.2006-82.

— 2015: The icemaster database and an analysis of aircraft aerodynamic icing accidents and incidents. DOT/FAA/TC-14/ 44, $135 \mathrm{pp}$.

Harrington, J. Y., G. Feingold, and W. R. Cotton, 2000: Radiative impacts on the growth of a population of drops within simulated summertime Arctic stratus. J. Atmos. Sci., 57, 766-785, https://doi.org/10.1175/1520-0469(2000)057<0766: RIOTGO $>2.0 . \mathrm{CO} ; 2$.

Hauf, T., and F. Schroeder, 2006: Aircraft icing research flights in embedded convection. Meteor. Atmos. Phys., 91, 247-265, https://doi.org/10.1007/s00703-004-0082-y.

Hoffmann, H. E., and J. Demmel, 1992: Analysis of three icing test flights reaching the aircraft-referred icing degree "severe." DLR-Forschungsbericht Rep. 90-34, 114 pp.

Hudson, J. G., and S. S. Yum, 2001: Maritime-continental drizzle contrasts in small cumuli. J. Atmos. Sci., 58, 915-926, https:// doi.org/10.1175/1520-0469(2001)058<0915:MCDCIS >2.0.CO;2.

Huffman, G. J., and G. A. Norman Jr., 1988: The supercooled warm rain process and the specification of freezing precipitation. Mon. Wea. Rev., 116, 2172-2182, https://doi.org/10.1175/15200493(1988)116<2172:TSWRPA > 2.0.CO;2.

Ikeda, K., R. M. Rasmussen, W. D. Hall, and G. Thompson, 2007: Observations of freezing drizzle aloft in extratropical cyclonic storms during IMPROVE-II. J. Atmos. Sci., 64, 3016-3043, https://doi.org/10.1175/JAS3999.1.

,-- E. Brandes, and F. McDonough, 2009: Freezing drizzle detection with WSR-88D radars. J. Appl. Meteor. Climatol., 48, 41-60, https://doi.org/10.1175/2008JAMC1939.1.

Isaac, G. A., S. G. Cober, J. W. Strapp, A. V. Korolev, A. Tremblay, and D. L. Marcotte, 2001: Recent Canadian research on in-flight aircraft icing. Can. Aeronaut. Space J., 47, 1-9.

—_, and Coauthors, 2005: First results from the Alliance Icing Research Study II. Preprints, AIAA 43rd Aerospace Science Meeting and Exhibit, Reno, NV, AIAA, AIAA 2005-252, https://doi.org/10.2514/6.2005-252.

Jeck, R. K., 2002: Icing design envelopes (14 CFR Parts 25 and 29, Appendix C) converted to a distance-based format. FAA Rep. DOT/FAA/AR-00/30, 55 pp., https://www.faa.gov/aircraft/ air_cert/design_approvals/small_airplanes/icing_protection_ systems/faa_documents/media/acereportar-00-30.pdf.

King, W. D., D. A. Parkin, and J. Handsworth, 1978: A hot-wire liquid water device having fully calculable response characteristics. J. Appl. Meteor., 17, 1809-1813, https://doi.org/ 10.1175/1520-0450(1978)017<1809:AHWLWD>2.0.CO;2.

Korolev, A. V., and G. A. Isaac, 2000: Drop growth due to high supersaturation caused by isobaric mixing. J. Atmos. Sci., 57, 1675-1685, https://doi.org/10.1175/1520-0469(2000)057<1675: DGDTHS $>2.0$.CO;2.

Kristjánsson, J. E., T. Nordeng, J. Kristiansen, T. Iverson, O. Saetra, M. Koltzow, B. E. K. Nygaard, and E. Irvine, 2010: Polar NWP-Norwegian activities. WMO Workshop-A
THORPEX Contribution to the Improvement of Polar Predictions on Weather to Seasonal Timescales, Oslo, Norway, WMO, https:/www.wmo.int/pages/prog/arep/wwrp/ new/documents/Kristjansson.pdf.

Kristovich, D., and N. F. Laird, 1998: Observations of widespread lake-effect cloudiness: Influences of lake surface temperature and upwind conditions. Wea. Forecasting, 13, 811-821, https://doi.org/ 10.1175/1520-0434(1998)013<0811:OOWLEC >2.0.CO;2.

Kubryn, M., R. Flemming, B. Bernstein, and J. Pietruszka, 2011: Flight tests in natural icing of the PZL Mielec M28 commuter turboprop airplane. Int. Conf. on Aircraft and Engine Icing and Ground Deicing, Chicago, IL, SAE 2011-38-104, https:// doi.org/10.4271/2011-38-0104.

Landolt, S., M. K. Politovich, A. Schwartz, K. Goodrich, and C. Phillips, 2014: Weather support for terminal area icing weather information. Sixth AIAA Atmospheric and Space Environments Conf. 2014, AIAA, AIAA 2014-2067, https:// doi.org/10.2514/6.2014-2067.

Lasher-Trapp, S., S. Anderson-Bereznicki, A. Shackelford, C. H. Twohy, and J. G. Hudson, 2008: The influence of droplet number concentration and giant aerosol particles on supercooled large drop formation in wintertime stratiform clouds. J. Appl. Meteor. Climatol., 47, 2659-2678, https://doi.org/ 10.1175/2008JAMC1807.1.

Le Bot, C., 2004: SIGMA: System of Icing Geographic Identification in Meteorology for Aviation. 11th Conf. on Aviation Range and Aerospace Meteorology, Hyannis, MA, Amer. Meteor. Soc., P6.5, http://ams. confex.com/ams/pdfpapers/ 81704.pdf.

Lee, T. F., F. J. Turk, and K. Richardson, 1997: Stratus and fog products using GOES-8-9 3.9- $\mu \mathrm{m}$ data. Wea. Forecasting, 12, 664-677, https://doi.org/10.1175/1520-0434(1997)012<0664: SAFPUG $>2.0 . \mathrm{CO} ; 2$.

Martin, G. M., D. W. Johnson, and A. Spice, 1994: The measurement and parameterization of effective radius of droplets in warm stratocumulus clouds. J. Atmos. Sci., 51, 1823-1842, https://doi.org/10.1175/1520-0469(1994)051<1823: TMAPOE $>2.0 . \mathrm{CO} ; 2$.

Marwitz, J. D., M. K. Politovich, B. C. Bernstein, F. M. Ralph, P. J. Neiman, R. Ashenden, and J. Bresch, 1997: Meteorological conditions associated with the ATR-72 aircraft accident near Roselawn, Indiana on 31 October 1994. Bull. Amer. Meteor. Soc., 78, 41-52, https://doi.org/10.1175/15200477(1997)078<0041:MCAWTA > 2.0.CO;2.

McDonough, F., and B. C. Bernstein, 2004: A case study of a Great Lakes supercooled large droplet icing cloud. 11th Conf. on Aviation, Range and Aerospace Meteorology, Hyannis, MA, Amer. Meteor. Soc., P6.15, https://ams.confex.com/ams/ pdfpapers/81884.pdf.

- - - and M. K. Politovich, 2004: The forecast icing potential algorithm. 42nd AIAA Aerospace Science Meeting and Exhibit, Reno, NV, AIAA, AIAA 98-0557, https:// doi.org/10.2514/6.2004-231.

- C. A. Wolff, and M. K. Politovich, 2008: Forecasting supercooled large drop icing conditions. 13th Conf. on Aviation, Range and Aerospace Meteorology, New Orleans, LA, Amer. Meteor. Soc., 13.5, https://ams.confex.com/ams/pdfpapers/ 134167.pdf.

Messinger, B. L., 1953: Equilibrium temperature of an unheated icing surface as a function of airspeed. J. Aeronaut. Sci., 20, 29-42, https://doi.org/10.2514/8.2520.

Miller, D., T. Ratvasky, B. Bernstein, F. McDonough, and J. W. Strapp, 1997: NASA/ FAA/NCAR supercooled large droplet 
icing flight research: Summary of winter 96-97 flight operations. 36th Aerospace Science Meeting and Exhibit, Reno, NV, AIAA, AIAA 98-0557, https://doi.org/10.2514/6.1998-577.

Miller, R. J., B. C. Bernstein, and L. Koch, 1999: A climatology of freezing rain in the Columbia Basin. Preprints, 17th Conf. on Weather Analysis and Forecasting, Denver, CO, Amer. Meteor. Soc., 48-52.

NTSB, 1996: Aircraft accident report: In-flight icing encounter and loss of control, Simmons Airlines, d.b.a. American Eagle flight 4184, Avions de Transport Regional (ATR) Model 72-212, N401MA, Roselawn Indiana, October 31, 1994. Safety Board Rep. NTSB/AAR-96/01, PB96-910401, DCA95MA001, Vol. $1,341 \mathrm{pp}$.

_ 1998: Aircraft accident report: In-flight icing encounter and uncontrolled collision with terrain, COMAIR flight 3272, Embraer EMB-120RT, N265 CA, Monroe MI, January 9, 1997. Safety Board Rep. NTSB/AAR-98/04, PB08-910404, DCA97MA017, 348 pp.

- 2002: Accident number DCA01MA031. Aviation Accident Final Rep., 9 pp., https://reports.aviation-safety.net/2001/ 20010319-0_E120_N266CA.pdf.

_ 2006: Incident number LAX06IA076. Aviation Incident Data Summary, https://www.ntsb.gov/_layouts/ntsb.aviation/brief2.aspx? ev_id=20060109X00033\&ntsbno $=$ LAX06IA076\&akey $=1$.

_ 2007: Crash during approach to Landing, Circuit City Stores, Inc. Cessna Citation 560, N500AT, Pueblo, Colorado, February 16, 2005. Aircraft Accident Rep. NTSB/AAR-07/ 02, 86 pp., https://ntsb.gov/investigations/AccidentReports/ Reports/AAR0702.pdf.

Pobanz, B., J. Marwitz, and M. Politovich, 1994: Conditions associated with large-drop regions. J. Appl. Meteor., 33, 1366-1372, https://doi.org/10.1175/1520-0450(1994)033<1366:CAWLDR> 2.0.CO;2.

Politovich, M. K., 1989: Aircraft icing caused by large supercooled droplets. J. Appl. Meteor., 28, 856-868, https://doi.org/10.1175/ 1520-0450(1989)028<0856:AICBLS > 2.0.CO;2.

_- , and B. C. Bernstein, 1995: Production and depletion of supercooled liquid water in a Colorado winter storm. J. Appl. Meteor., 34, 2631-2648, https://doi.org/10.1175/ 1520-0450(1995)034<2631:PADOSL>2.0.CO;2.

Pruppacher, H. R., and J. D. Klett, 1978: Microphysics of Clouds and Precipitation. D. Reidel, $714 \mathrm{pp}$.

Rasmussen, R. M., and Coauthors, 1992: Winter Icing and Storms Project (WISP). Bull. Amer. Meteor. Soc., 73, 951-974, https:// doi.org/10.1175/1520-0477(1992)073<0951:WIASP>2.0.CO;2.

_ B. B. C. Bernstein, M. Murakami, G. Stossmeister, J. Reisner, and B. Stankov, 1995: The 1990 Valentine's Day arctic outbreak. Part I: Mesoscale and microscale structure and evolution of a Colorado Front Range shallow upslope cloud. J. Appl. Meteor., 34, 1481-1511, https://doi.org/10.1175/ 1520-0450-34.7.1481.

— I. Geresdi, G. Thompson, K. Manning, and E. Karplus, 2002: Freezing drizzle formation in stably stratified layer clouds: The role of radiative cooling of cloud droplets, cloud condensation nuclei, and ice initiation. J. Atmos. Sci., 59, 837-860, https:// doi.org/10.1175/1520-0469(2002)059<0837:FDFISS >2.0.CO;2.

Ratvasky, T. P., B. Barnhart, and S. Lee, 2010: Current methods for modeling and simulating icing effects on aircraft performance, stability and control. J. Aircr., 47, 201-211, https://doi.org/ 10.2514/1.44650.

Rauber, R. M., L. S. Olthoff, M. K. Ramamurthy, and K. E. Kunkel, 2000: The relative importance of warm rain and ice processes in freezing precipitation events. J. Appl. Meteor., 39,
1185-1195, https://doi.org/10.1175/1520-0450(2000)039<1185: TRIOWR $>2.0 . \mathrm{CO} ; 2$.

Reehorst, A., D. Brinker, M. Politovich, D. Serke, C. Ryerson, A. Pazmany, and F. Solheim, 2009: Progress towards the remote sensing of aircraft icing hazards. NASA/TM-2009215828, 22 pp., https://ntrs.nasa.gov/archive/nasa/casi.ntrs.nasa.gov/ 20100001322.pdf.

Rosenfeld, D., and Coauthors, 2013: The common occurrence of highly supercooled drizzle and rain near the coastal regions of the western United States. J. Geophys. Res. Atmos., 118, 9819-9833, https://doi.org/10.1002/jgrd.50529.

Sand, W. R., W. A. Cooper, M. K. Politovich, and D. L. Veal, 1984: Icing conditions encountered by a research aircraft. J. Climate Appl. Meteor., 23, 1427-1440, https://doi.org/10.1175/07333021-23.10.1427.

Serke, D., M. King, and A. Reehorst, 2015: Initial results from radiometer and polarimetric radar-based icing algorithms compared to in-situ data. Int. Conf. on Icing of Aircraft, Engines and Structures, Prague, Czech Republic, SAE, 2015-012153, https://doi.org/10.4271/2015-01-2153.

— S. Tessendorf, B. Geerts, J. R. French, B. Pokharel, D. Jacobson, and D. Albo, 2017: Initial performance evaluation of a radar-based supercooled water detection algorithm during the SNOWIE Field Campaign. 38th Conf. on Radar Meteorology, Chicago, IL, Amer. Meteor. Soc., 6, https://ams.confex.com/ ams/38RADAR/webprogram/Paper320660.html.

Smith, W. L., Jr., P. Minnis, C. Fleeger, D. Spangenberg, R. Palikonda, and L. Nguyen, 2012: Determining the flight icing threat to aircraft with single-layer cloud parameters derived from operational satellite data. J. Appl. Meteor. Climatol., 51, 1794-1810, https://doi.org/10.1175/JAMC-D-12-057.1.

Strapp, J. W., and Coauthors, 2003: Wind tunnel measurements of the response of hot-wire liquid water content instruments to large droplets. J. Atmos. Oceanic Technol., 20, 791-806, https://doi.org/ 10.1175/1520-0426(2003)020<0791:WTMOTR > 2.0.CO;2.

Tafferner, A., T. Hauf, C. Leifeld, T. Hafner, H. Leykauf, and U. Voigt, 2003: ADWICE: Advanced Diagnosis and Warning System for Aircraft Icing Environments. Wea. Forecasting, 18, 184-203, https://doi.org/10.1175/1520-0434(2003)018<0184: aadaws $>2.0$. co; 2 .

Thompson, G., and T. Eidhammer, 2014: A study of aerosol impacts on clouds and precipitation development in a large winter cyclone. J. Atmos. Sci., 71, 3636-3658, https://doi.org/ 10.1175/JAS-D-13-0305.1.

- P. R. Field, R. M. Rasmussen, and W. D. Hall, 2008: Explicit forecasts of winter precipitation using an improved bulk microphysics scheme. Part II: Implementation of a new snow parameterization. Mon. Wea. Rev., 136, 5095-5115, https:// doi.org/10.1175/2008MWR2387.1.

_ - M. Xu, and P. A. Jimenez, 2017a: Towards improving representation of sub-grid-scale clouds in WRF and application to aircraft icing forecasts. 18th Conf. on Aviation, Range and Aerospace, Seattle, WA, Amer. Meteor. Soc., 7.2, https:// ams.confex.com/ams/97Annual/webprogram/Paper313599.html.

— M. K. Politovich, and R. M. Rasmussen, 2017b: A numerical weather model's ability to predict characteristics of aircraft icing environments. Wea. Forecasting, 32, 207-221, https:// doi.org/10.1175/waf-d-16-0125.1.

Vivekanandan, J., D. S. Zrnic, S. M. Ellis, R. Oye, A. V. Ryzhkov, and J. Straka, 1999: Cloud microphysics retrieval using S-band dual-polarization radar measurements. Bull. Amer. Meteor. Soc., 80, 381-388, https://doi.org/10.1175/1520-0477(1999) $080<0381$ :CMRUSB $>2.0$. CO;2. 
Whiteman, C. D., S. Zhong, W. J. Shaw, J. M. Hubbe, X. Bian, and J. Mittelstadt, 2001: Cold pools in the Columbia basin. Wea. Forecasting, 16, 432-447, https://doi.org/10.1175/15200434(2001)016<0432:CPITCB > 2.0.CO;2.

Williams, E., M. Donovan, D. Smalley, R. Hallowell, E. Griffin, K. Hood, and B. Bennett, 2015: The 2013 Buffalo Area Icing and Radar Study (BAIRS). MIT Lincoln Laboratory Project Rep. ATC-419, 154 pp.

Wolff, C. A., F. McDonough, M. K. Politovich, and G. M. Cunning, 2009: The forecast icing product: Recent upgrades and improvements. First AIAA Atmospheric and Space Environments Conf., Aerospace Science Meeting and Exhibit, San Antonio, TX, AIAA, AIAA 2009-3531, https://doi.org/10.2514/ 6.2009-3531.

Wood, R., 2005: Drizzle in stratiform boundary layer clouds. Part I: Vertical and horizontal structure. J. Atmos. Sci., 62, 3011-3033, https://doi.org/10.1175/JAS3529.1.

Wright, W. B., 1999: User manual for the NASA Glenn ice accretion code LEWICE version 2.0. NASA Contractor Rep. 1999-209409, $182 \mathrm{pp}$ 